\title{
LA FUERZA SIMBÓLICA DE LOS DERECHOS HUMANOS ${ }^{1}$
}

\author{
Marcelo Neves \\ Escola de Direito de São Paulo
}

RESUMEN. Los derechos humanos son construcciones y conquistas político-jurídicas de la modernidad que responden de un lado a las demandas sociales de autonomía de las diversas esferas de comunicación (se trataría de evitar la represión de la autonomía jurídica o política por un código empíricamente más fuerte, en nuestros días, el económico) y de otro a la demanda - en las condiciones de disenso estructural propias de la sociedad moderna (estatal e internacional) — de inclusión de personas y grupos. Sin embargo, los derechos humanos enfrentan diversas paradojas. De ellas, las que se refieren a su positivización y a su internacionalización son las aquí abordadas. En este ámbito de problemas, la fuerza simbólica de los derechos humanos aparece como ambivalente: por un lado, lleva a la afirmación y realización generalizada de los derechos; por otro lado, actúa como forma de manipulación política encubriendo situaciones de falta de derechos o, de forma todavía más grave, posibilitando la opresión política y con ella violaciones escandalosas de los mismos. El uso retórico de los derechos humanos por Estados Unidos de América merece una aproximación crítica en cuanto que pone
Abstract. Human rights are modern constructions and political-legal achievements which answer, on the one hand, the social demands for autonomy made by the different areas of communication (their aim is to avoid the repression of legal or political autonomy by an empirically stronger code, nowadays, the economic) and, on the other hand, they answer the demand for inclusion of persons and groups, in the conditions of structural dissent which characterize modern society (state and international). However, human rights face various paradoxes. Of these, the ones dealt with here are those which refer to their becoming positive and international. When referring to these problems, the symbolic strength of human rights appears to be ambivalent: on the one hand, it leads to the affirmation and the generalized exercise of the rights; on the other hand, it acts as a kind of political manipulation hiding situations where rights are lacking, or even more seriously, enabling political oppression to exist and, as a result, making possible scandalous violations of these rights. The rhetoric use of human rights by the United States of America deserves a critical approach, in so far as

\footnotetext{
${ }^{1}$ El presente artículo es una versión revisada de la conferencia pronunciada en la XVIII Conferência Nacional dos Advogados, realizada en Salvador, Bahia, del 11 al 15 de Noviembre de 2002.
} 
de manifiesto cómo la fuerza simbólica negativa contradice y pone en riesgo la propia afirmación simbólica y el logro de los derechos humanos en la sociedad mundial compleja y heterogénea del presente. it demonstrates the way in which negative symbolic strength contradicts and puts at risk the symbolic affirmation itself and also the achievement of human rights in the complex and heterogeneous world society that exists today.

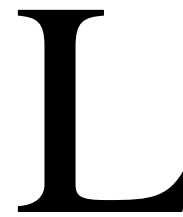

a conexión de dos expresiones tan vagas, ambiguas y, tal vez pudiera decirse, pretenciosas en el título de esta conferencia torna mi exposición especialmente delicada. Es cierto que éste es un problema inherente a todos los conceptos relevantes en las áreas del conocimiento referentes al mundo cultural y social. Sin embargo, en lo que concierne al adjetivo ‘simbólico' y a la expresión 'derechos humanos', se puede observar una abusiva exageración en sus usos, sin que se aprecie una especial preocupación por sus contenidos significativos. En el primer caso, en lo tocante al término 'simbólico', la cuestión surge más bien en relación con la dimensión cognoscitiva: hay una variedad de usos que dan al término muchas veces un giro teórico poco fructífero. En ese sentido, Umberto Eco calificó aquella ocasión en la que se reunieron los editores del diccionario filosófico de Lalande para discutir públicamente sobre la definición de 'símbolo' como "uno de los momentos más patéticos de la lexicografía filosófica”, enfatizando que el diccionario "no concluye: la conclusión indirecta a la que Lalande invita es que el símbolo es muchas cosas, y ninguna. En síntesis, no se sabe lo que es” (Eco, 1984: 199 s. -tr. br., 1991: 196; cf. Lalande, org., 1992: 1079-81). ${ }^{2}$ En el segundo caso, en lo concerniente a los 'derechos humanos', el problema se plantea sobre todo (aunque no sólo) respecto a la dimensión normativa. La idea de que los derechos humanos son “esenciales”, fundamentales y universales conduce a una lucha por incluir ciertos contenidos y excluir otros de su ámbito semántico, en función de cuáles sean los valores particulares de los respectivos grupos y del contexto histórico correspondiente. Con cierto cinismo o, como mínimo, ironía, podría decirse en relación con ‘derechos humanos’-recuperando la terminología de Lévi-Strauss (1973: XLIX s., nota 1, tr. br., 1974: 35, nota 37)- que se trata de un "significante fluctuante” o de "valor simbólico cero", cuya función o eficacia sería "la de oponerse a la ausencia de significado sin comportar por sí mismo significado alguno”. Otra alternativa consistiría en afirmar, apoyándonos en el modelo deconstructivista, que la expresión

\footnotetext{
2 En relación con la ambigüedad de ‘símbolo’, ‘simbólico’ y 'simbolismo', ver Neves, 1994a: $11 \mathrm{~s}$.
} 
'derechos humanos' constituye un "significante vacío" (Laclau, 1994). Estas distintas posibilidades, sin embargo, no nos serían de gran ayuda para abordar el problema del que nos ocupamos en esta conferencia, sino que nos servirían sólo para cuestionar el uso semánticamente arbitrario del significante 'derechos humanos'. Así las cosas, es preciso reconstruir el campo de sentido predominante en que los derechos humanos son utilizados en el discurso político y jurídico contemporáneo para, a partir de ahí, enfrentar con la mayor claridad posible el problema de su fuerza simbólica.

En la exposición que sigue, pretendo, en primer lugar, delimitar muy brevemente el sentido en que empleo el término ‘simbólico’ y la expresión 'fuerza simbólica' en el ámbito de la presente conferencia, incidiendo en las ambigüedades que vienen aparejadas en el uso de este término (II). A continuación, abordaré la cuestión semántica del significado y la pragmática de los portadores de los derechos humanos, señalando que no se trata de derechos "eternos", sino de construcciones y conquistas político-jurídicas de la modernidad que han posibilitado diferentes formas concretas de positivación e "interpretación" de acuerdo con el contexto cultural y social respectivo; en esta parte, me referiré también a las paradojas de los derechos humanos, y a las formas de su desarrollo y superación (III). Apoyándome en estos presupuestos, entraré en el núcleo de mi exposición caracterizando la fuerza simbólica de los derechos humanos como ambivalente: por un lado, propicia la afirmación y realización generalizada de derechos relacionados con la inclusión jurídica en condiciones de disenso estructural; por otro lado, actúa como forma de manipulación política, ya sea para encubrir situaciones de carencia de derechos, o bien, más gravemente, para dar cobertura a la opresión política, implicando, en ese caso, violaciones escandalosas de los propios derechos humanos sobre amplios segmentos de la población civil inocente. A ese respecto, me concentraré, en primer lugar, en la fuerza simbólica de los derechos humanos en el plano de los Estados (IV) y, después, la abordaré en el contexto internacional y mundial (V). Finalmente, intentaré formular una breve crítica al uso retórico de los derechos humanos por la única superpotencia que existe actualmente, los Estados Unidos de América, uso cuya fuerza simbólica negativa contradice y pone en riesgo la propia afirmación simbólica y la realización de los derechos humanos en la compleja y heterogénea sociedad mundial del presente (VI).

\section{II}

Muy comúnmente, la referencia al término 'simbólico' sugiere que nos encontramos ante algo diferente de lo fáctico, de lo real. Sin embargo, toda la dimensión de lo semiótico, no sólo lo simbólico en el sentido que yo pretendo darle aquí, es realidad que se refiere a realidad. Constituye un 
plano reflexivo de la realidad construida socialmente. De ahí la paradoja de los signos: son formas de referencia a la realidad que, en cierto modo, construyen esa misma realidad y constituyen, ellos mismos, parte de la realidad social, pudiendo ser referidos como objetos (signos-objeto) en otros planos semióticos. No se trata, sin embargo, de planos en el sentido formal de la teoría de los tipos (Russell, 1968,: 75-80). No sólo entre significante y significado existe una circularidad dinámica en el proceso de construcción de las significaciones, sino que también la relación entre signos referentes y signos referidos, aunque asimétrica, incluye “entrelazamientos” (cf. Hofstadter, 1979,: el esp. 21 s., tr. br., 2001: esp. 23 ss.), auto-referencia o circularidad: así, por ejemplo, el lenguaje judicial, cuyo objeto es el lenguaje legal, al interpretarlo, construye, en parte, el sentido de éste, de tal manera que la distinción entre lenguaje-objeto y metalenguaje resulta relativizada (cf. Neves, 1994a,: 82, 2000: 146 y 148). En suma, los signos son parte de la realidad social que, paradójicamente, se refieren a esta misma realidad social, autoconstruyéndola.

Pero con la dimensión simbólica en sentido estricto, esta cuestión adquiere una nueva especificidad. Esto significa que no adopto un concepto holístico, inespecífico de lo simbólico, no confundo lo simbólico con lo semiótico (Cassirer, 1944,: 24 ss., tr. br., 1972: 49 ss.; 1988: 1 ss.), ni defino la estructura social simplemente como simbólica (Lévi-Strauss, 1973: XIX, tr. br., 1974: 9; 1958: 305 s.) $)^{3}$, ni tampoco reduzco la política a una dimensión de lo simbólico (Edelman, 1967, 1977). En el uso que hago aquí, que encuentra amplio respaldo en las ciencias sociales en general y en la propia semiología, lo simbólico constituye sólo una dimensión (aunque enormemente relevante) de lo social y de lo propio semiótico (cf. Neves, 1994a: 24 ss). Lo simbólico implica un lenguaje o discurso en el que hay un desplazamiento de sentido hacia otra esfera de significaciones (vid. Figura 1). El actuar simbólico es connotativo en la medida en que adquiere un sentido mediato e impreciso, que se añade a su significado inmediato y manifiesto (Gusfield, 1986: 170, 1967: 177) y que prevalece en relación con este último. Así, por ejemplo, el significado político latente de un texto con sentido manifiestamente jurídico puede ser inmensamente más relevante que éste. A este respecto, estudiando un caso de legislación simbólica -la "ley seca” en los Estados Unidos-, Joseph Gusfield subrayó cómo muchas leyes, por sus contenidos, resultan dignificadas tanto en caso de violación generalizada

\footnotetext{
${ }^{3}$ Es bajo la innegable influencia de la antropología estructuralista de Lévi Strauss que Bourdieu y Passeron desarrollan el concepto de "violencia simbólica”, "eficacia simbólica” o “poder simbólico” (cf. Bourdieu / Passeron, 1970: 13-84; Bourdieu, 1971: 298 ss., 1982: esp. 97-161, 1989: esp. 48 ss. y 552 ss.).
} 


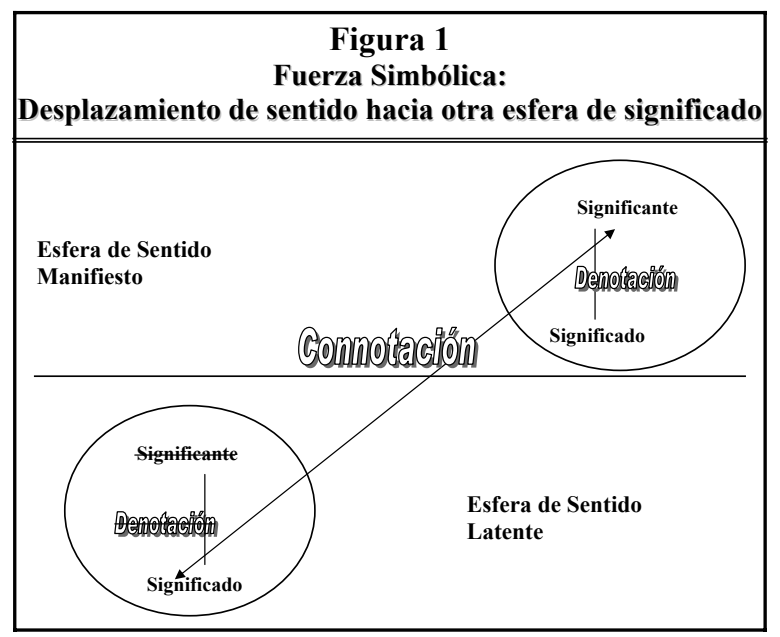

cuanto en la hipótesis de cumplimiento sistemático (Gusfield, 1967: 177), para resaltar justamente que la fuerza político-simbólica de esa legislación estaba relacionada con su falta de eficacia jurídica.

En un estudio anterior sobre constitucionalización simbólica (Neves, 1994a), hice hincapié en el carácter negativo de lo simbólico para la normatividad constitucional. En aquel contexto y ámbito específico de problemas, se destacaba la hipertrofia de la dimensión político-simbólica del texto constitucional en detrimento de su eficacia jurídica. La constitucionalización simbólica consistiría en una “superexplotación” del Derecho por la política, de tal manera que la propia autonomía operacional del sistema jurídico estaría con ello perjudicada (ibídem: 132). No se negaba que toda Constitución tiene una dimensión simbólica, ni que ésta puede servir a la propia normatividad constitucional, pero sí se restringía el concepto de constitucionalización simbólica a esas situaciones de hipertrofia de lo político-simbólico en perjuicio de la fuerza normativo-jurídica del texto constitucional. Tampoco se negaba el carácter positivo de la constitucionalización simbólica en el proceso de superación del autoritarismo y la lucha por la democratización (ibídem: 162), pero no se ponía esa dimensión en primer plano.

En el presente contexto, al tratar de la "fuerza simbólica de los derechos humanos”, cabe más bien subrayar la ambivalencia de lo simbólico. Es verdad que, en el ámbito de lo normativo, cuando enfatizamos la fuerza simbólica, sugerimos un cierto grado de falta de fuerza normativa, al menos de momento, de los correspondientes actos, discursos, declaraciones o textos. Pero el carácter connotativo de declaraciones, discursos, acciones y textos simbólicos no siempre sirve al mantenimiento del statu quo de carencia de 
los respectivos derechos. La dimensión simbólica de lo normativo puede contribuir justamente a la superación de situaciones concretas de negación de los derechos. La referencia simbólica a una determinada institución jurídica caracterizada por un alto grado de ineficacia normativo-jurídica posibilita tanto el encubrimiento de esa realidad, e incluso la manipulación política para usos contrarios a la concretización y efectividad de las respectivas normas, cuanto también una amplia realización en el futuro del modelo normativo en cuestión. En efecto, la fuerza simbólica de acciones, textos, declaraciones y discursos de carácter normativo puede traer aparejado tanto el mantenimiento de una situación de falta de derechos como la movilización para la construcción y realización de los mismos. Esta ambivalencia significa que lo simbólico no se reduce a lo "ideológico", en el sentido de ilusión negadora de otras alternativas, ni a lo "retórico”, en el sentido de una persuasión no comprometida con el acceso a los derechos, ya que también incorpora, paradójicamente, el espacio para la crítica del modelo normativo que se presenta como fachada. Además, cualquier recurso a la fuerza simbólica implica siempre un riesgo. Por un lado, la afirmación simbólica de derechos e instituciones jurídicas sin compromiso alguno con el acceso real a los mismos o a su realización efectiva puede llevar a la apatía pública y al cinismo de las élites (Neves, 1994a: 112 y 161; Kindermann, 1989: 270) como también conducir a la movilización social que conduzca a su concreción normativa y a su realización efectiva. En ese sentido, subraya Friedrich Müller en referencia a los textos normativos: “A fin de cuentas, no se decretan impunemente textos de normas y textos constitucionales que hayan sido concebidos con precomprensión insincera. Los textos pueden devolver el golpe [zurückschlagen]” (1997: 56, tr. br., 1998: 105). Por otro lado, también el recurso crítico a la fuerza simbólica para promover la efectividad de los modelos jurídicos y el acceso a los derechos solemnemente declarados puede volverse en contra negativamente generando una apatía pública y una desconfianza en las propias posibilidades reales de conquista de derechos, así como un desprecio cínico por parte de las élites dominantes en relación con la inocuidad de sus críticos, mientras no se tomen en consideración de forma adecuada los límites socio-estructurales del funcionamiento de las instituciones en cuestión y el goce efectivo de los derechos por la masa de excluidos. El Derecho no es una esfera aislada en el mundo social, sino que existe una variedad de presupuestos no-jurídicos (económicos, políticos, culturales, científicos, técnicos, educativos etc.) de lo jurídico.

En el presente, estas ambivalencias de la fuerza simbólica de lo normativo se manifiestan de manera especialmente relevante en el ámbito de los derechos humanos. Sin embargo, antes de entrar en el tema central de nuestra conferencia, es menester delimitar para nuestros fines el campo semántico 
(de significación) y, de manera inseparable de éste, el campo pragmático (de los titulares) de los derechos humanos.

\section{III}

Cuando me refiero a los derechos humanos, no apunto a una noción de derechos eternos, esenciales, ahistóricos. Los derechos humanos constituyen una conquista de la sociedad moderna, pudiendo ser también caracterizados como una construcción o "invención” de la modernidad (cf. Bobbio, 1992; Lefort, 1981). Con ello no se quiere negar que haya antecedentes históricos de la idea de derechos humanos ya en la Antigüedad, que persisten hasta el inicio de la era moderna (cf. Gerhardt, 20 ss.). Pero tampoco se debe concluir de aquí que los derechos humanos no hayan sido "inventados” (en el sentido de socialmente construidos) en el ámbito de una nueva semántica de la sociedad moderna ${ }^{4}$, en correspondencia con transformaciones radicales de la estructura social que implicarán la denominada "Revolución de los derechos humanos” (Gauchet, 1989). Evidentemente, ninguna “invención”, en tanto que construcción social, surge de la nada. Los derechos humanos se remontan a nociones pre-modernas en el ámbito de la filosofía, de la teología y de la política (cf. Brunkhorst, 2000, 2002), pero constituyen un nuevo artefacto social que emerge con la modernidad. En este sentido, se puede observar que la idea moderna de los derechos humanos viene a presentarse como un sustituto de la noción más antigua de Derecho natural, de tal manera que su fundamentación es una "herencia que nos dejó la decadencia del antiguo Derecho natural europeo” (Luhmann, 1993a: 539). Pero mientras que en la tradición del Derecho natural pre-moderno las expectativas cognoscitivas y normativas se entremezclan (la "naturaleza esencial" como modelo normativo) y hay una suerte de preponderancia del pasado en relación con el futuro, determinando y fijando aquél a éste, el surgimiento de los derechos humanos implica tanto la distinción entre lo normativo y lo cognoscitivo como una orientación hacia el futuro. Los derechos humanos se relacionan, por tanto, con la "apertura de la sociedad moderna hacia el futuro” (Luhmann, 1993b: 115). Sin embargo, no se trata simplemente del reconocimiento y confirmación de esa apertura hacia el futuro. Al reconocimiento y a la confirmación cognitivos de la contingencia social y a la incertidumbre respecto del futuro en el ámbito de la sociedad moderna, los derechos humanos responden con la demanda normativa de estructuración de la "apertura hacia el futuro". Eso significa que los derechos humanos sirven para la transformación de la complejidad desestructurada en comple-

\footnotetext{
${ }^{4}$ En sentido contrario, vid. Gehardt, 1999: especialmente 26 s.
} 
jidad estructurada ${ }^{5}$ al incluir la pretensión de justificar ciertas expectativas normativas y excluir la validez jurídica de otras. Este papel estructurador de la apertura hacia el futuro y de la complejidad se relaciona con demandas normativas sensibles al reconocimiento cognoscitivo del exceso de posibilidades y riesgos inherentes a la sociedad moderna.

De la misma manera que tienen relación con la hipercomplejidad, el alto grado de contingencia y la amplia apertura hacia el futuro -que caracterizan a la sociedad moderna (Luhmann, 1981: 80, 1992: 93 ss., 1987b: 344 ss.)-, los derechos humanos, así como ya se dijo respecto de los derechos fundamentales positivizados constitucionalmente (Luhmann, 1986: 23-25), van referidos al "peligro de desdiferenciación", sirviendo a la dinámica de un orden social cuyas comunicaciones permanecen "abiertas a la diferenciación", es decir, al "mantenimiento de un orden diferenciado de comunicación". En otras palabras, puede decirse que los derechos humanos responden a las exigencias sociales de autonomía de las diversas esferas de comunicación y de discursos. Aunque desde una perspectiva crítica y con otro lenguaje, ya Marx (1988: 361 ss.), al definir los "derechos humanos" ("en contraposición a los derechos del ciudadano") como "derechos de quien es miembro de la sociedad burguesa, esto es, del hombre egoísta” (364), sugería una conexión con un problema de diferenciación social: "El hombre no fue por ello liberado de la religión, obtuvo la libertad religiosa. No fue liberado de la propiedad, obtuvo la libertad de propiedad. No fue liberado del egoísmo de la industria, obtuvo la libertad industrial” (369). ${ }^{6}$ Más tarde, las críticas de Lefort (1981) a las tendencias totalitarias contrarias a los derechos humanos también apuntaban en esa dirección: a que se reconduzca la institucionalización de esos derechos hacia el "desintrincamiento" de poder, ley y saber, acentuando que no se trata de una escisión de esos dominios (1981: 64, tr. br., 1987: 53). En esta perspectiva, la subordinación del Derecho y del saber a la política es incompatible con los derechos humanos. Pero el "desintrincamiento" (la diferenciación) puede referirse aquí de forma más general a las diversas esferas de comunicación (subsistemas) o juegos del lenguaje (discursos) con pretensión de autonomía en condiciones de complejidad. La negación de la diferenciación o la represión de la autonomía sistémica o discursiva por un código empíricamente más fuerte en un contexto social determinado, hoy antes el económico que el político, actúa en sentido opuesto a la positivización

\footnotetext{
${ }^{5}$ Sobre la distinción entre complejidad estructurada y no estructurada, cf. Luhmann, 1987a: 383, 1987b: 6s. De forma paralela, distingue Luhmann entre complejidad indeterminada/indeterminable y determinada/determinable (1971:300-302, 1975: 209 ss).

${ }^{6}$ Sin embargo, en su postura crítica, Marx hablaba de "descomposición del hombre" (1988:357), no de diferenciación social.
} 
de los derechos humanos. Una expansión de la economía o de la política con efectos socialmente “desdiferenciadores” trae aparejado no sólo el rechazo de la autonomía del Derecho (legalidad y constitucionalidad en el ámbito de los Estados o, de forma más comprensiva, rule of law y due process of law), presupuesto de realización de los derechos humanos, sino también la ocultación de las libertades en los ámbitos de la ciencia, el arte, la educación etc.

Por otra parte, los derechos humanos no se refieren solamente a la pluralidad y autonomía de sistemas sociales y discursos, resistiendo el peligro de la "desdiferenciación” (sobre todo política y económica, pero también religiosa, mediática, etc.) de la sociedad, sino que también implican la inclusión de personas y grupos. Desde el punto de vista pragmático de los portadores o destinatarios, los derechos humanos tienen la pretensión de ser universalmente válidos. Todo hombre es portador de los derechos humanos. Mientras los modelos iusnaturalistas que se remontan al pensamiento europeo antiguo tendían a excluir ciertas clases de hombres (esclavos, mujeres y, en cierta manera, también a los extranjeros) para construir un orden jerárquico entre los hombres en relación con sus derechos, los derechos humanos (modernos) tienen la pretensión de una inclusión generalizada de todos los hombres en el ámbito jurídico. Por tanto, en este sentido, no constituyen una expresión ética de valores colectivos particulares porque se relacionan con un discurso con pretensión normativa de universalidad pragmática7 ${ }^{7}$. Desde esa perspectiva, los derechos humanos pueden definirse como expectativas normativas de inclusión jurídica de todos y cada una de las personas en la sociedad (mundial) y, por consiguiente, de acceso universal al Derecho en cuanto subsistema social (autónomo). Mientras que en el concepto de justicia, la noción de igualdad está en primer plano, en el concepto de derechos humanos es la idea de inclusión jurídica como acceso al Derecho la que es central, aunque no sólo la primera presupone la segunda, sino que esta última se orienta en el sentido de aquélla. La exclusión jurídica de amplios grupos humanos se presenta justamente como la dimensión negadora de los derechos humanos que, paradójicamente, fortifica su semántica y también las expectativas normativas correspondientes. De forma diferente a la ciudadanía en sentido amplio, que apunta hacia la inclusión jurídica generalizada en el ámbito de un orden estatal particular (Neves, 2000: 134 ss.), los derechos humanos se refieren a la inclusión jurídica en el plano de la sociedad mundial. Bajo ese aspecto, el propio derecho a la ciudadanía puede verse como una dimensión reflexiva de

\footnotetext{
${ }^{7}$ Sobre este aspecto, aunque con otros presupuestos y consecuencias teóricas, tiene razón Habermas (cf., p. ej., 1998a: esp. 162 s.).
} 
los derechos humanos ${ }^{8}$. Por tanto, los derechos humanos tienen pretensión de afirmarse tanto frente a los diversos órdenes estatales, como frente al orden internacional, así como ante la pluralidad de órdenes extra-estatales en los que las expectativas normativas tienen relevancia estructural.

Pero el universalismo de los derechos humanos como exigencia de inclusión jurídica generalizada en el ámbito de la sociedad mundial se relaciona con la heterogeneidad de personas y grupos en lo que se refiere a las expectativas normativas, valores e intereses característicos de la modernidad. En un horizonte pre-moderno de un orden político-jurídico excluyente y represor de valores, expectativas e intereses divergentes de los dominantes, los derechos humanos eran inconcebibles. La semántica de los derechos humanos se desenvuelve justamente en la medida en que determinadas transformaciones estructurales llevan a una pluralidad contradictoria de expectativas, valores e intereses no sólo entre las diversas esferas discursivas y sistémicas con pretensión de autonomía, sino también entre las personas y grupos que se encuentran en el ámbito del mismo campo discursivo o sistémico. Esto significa que los derechos humanos tienen muy poco que ver con un consenso en condiciones discursivas ideales para la búsqueda de tal consenso. Al contrario, la idea de derechos humanos surge en el contexto del disenso estructural que adviene con el surgimiento de la sociedad moderna, disenso este (insisto) que concierne tanto a la integración sistémica conflictiva entre esferas de comunicación con pretensión de autonomía (Luhmann, 1997: esp. 603 s.) y a la heterogeneidad de juegos del lenguaje (Wittgenstein, 1997: 250, § 23; Lyotard, 1979: 20 ss.; Welsch, 1991, 1996: 401 ss.; Teubner, 1996; Ladeur, 1992: esp. 41-45), como a la divergencia de valores, expectativas e intereses de las personas y grupos (v. Figura 2). Desde esta perspectiva, tiene razón Welsch cuando afirma -aunque admitiendo que tal interpretación resulta un tanto forzada- que los derechos humanos son, en su núcleo, “derechos al disenso” (1991: 180). Un orden fundado en el consenso respecto a los contenidos valorativos prescinde de los derechos humanos porque la virtud debida a la armonía social, presente ya en el plano de las estructuras normativas, incluye a los que aceptan el orden respectivo y excluye, no teniendo en cuenta o reprimiendo, a los que no concuerdan con él. Tampoco cabría hablar de derechos humanos a partir de reglas procedimentales ideales que permitieran llegar a un resultado consensual o, en otras palabras, teniendo como criterio las condiciones ideales del discurso orientado a la comprensión (cf., p. ej.,

\footnotetext{
${ }^{8}$ A su vez, en planos reflexivos diferentes, se define de un lado "la ciudadanía como el derecho a tener derechos” (Lafer, 1988:146 ss.) y se habla, por otra parte, con pretensión de fundamentación, de “derecho a los derechos humanos” (Brunkhorst/ Köhler / Lutz-Bachmann, eds., 1999).
} 
Habermas, 1992: 187-207). Los derechos humanos sirven más bien para permitir la convivencia en condiciones reales de disenso estructural. Si quisiéramos hablar de una moral universalista moderna que estaría presupuesta en la idea de derechos humanos, esa moral debería ser entendida como moral del disenso. Por ejemplo, la tortura y otros métodos de represión contrarios a los derechos humanos van dirigidos exactamente a la negación del disenso. El problema de los derechos humanos sólo se manifiesta cuando el disenso se hace también presente. En los espacios de consenso (y éstos, sin duda, no son pocos ni restringidos) o en condiciones favorables a un consenso racional alcanzado mediante el discurso, los derechos humanos son prescindibles. Éstos surgen como demanda funcional y pretensión normativa de hacer posible la imposible convivencia social en el contexto de conflictos intersistémicos o interdiscursivos y en el contexto de divergencias personales y grupales referentes a valores, expectativas normativas e intereses. Esto no quiere decir que los derechos humanos conduzcan a un relativismo absoluto. La inclusión jurídica universal y la autonomía discursiva constituyen el marco dentro del que las diferencias han de ser soportadas. Por lo tanto, cualquier forma de "fundamentalismo" -en un sentido muy amplio de esa expresión: sea el religioso, étnico o político, referente a personas y/o grupos que promueven un orden excluyente de valores, incluso en lo económico, que tiende a negar la autonomía de otras esferas de comunicación y discurso- actúa en la dirección opuesta al universalismo de los derechos humanos como posibilitadores de la convivencia social en condiciones de disenso estructural. De ahí que, en la medida en que los derechos humanos pretenden dar apoyo a respuestas normativas a ese disenso estructural, exigen una institucionalización de procedimientos abiertos a la heterogeneidad cultural, a la complejidad sistémica y a la pluralidad discursiva de la sociedad mundial que los garantice. En relación con estos procedimientos, sí se impone, funcional y normativamente, una base consensual amplia. No obstante, ese consenso procedimental es exigido para asegurar el disenso estructural inherente a los derechos humanos. El problema reside exactamente en el hecho de que los derechos humanos, en el contexto de la sociedad mundial del presente, al contrario de lo que sucede con los derechos fundamentales en el ámbito estricto del Estado democrático de Derecho, constituyen expectativas normativas carentes de una institucionalización satisfactoria tanto en la dimensión personal (consenso sobre procedimientos), como en la material (identificación de significados) y en la temporal (normativización).

\footnotetext{
${ }^{9}$ Se trata ahora del concepto más amplio de Institución en el sentido de Luhmanm: "Las instituciones son expectativas de comportamiento generalizadas temporal, material y socialmente que constituyen, en cuanto tales, la estructura de los sistemas sociales” (1986:13).
} 


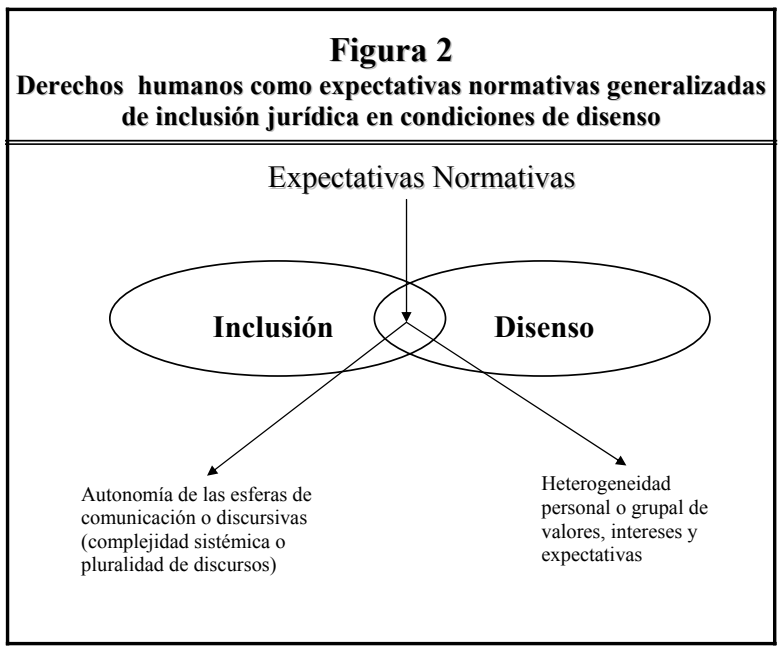

Esto nos pone, en otro plano, ante el problema de la vaguedad de la expresión 'derechos humanos', que implica el disenso en el propio ámbito material, personal y temporal de validez de los mismos. Es decir, aquí se trata de un disenso sobre lo que son los derechos humanos en cuanto derechos a la inclusión jurídica generalizada. Es cuestionable la tesis de que la propia idea de derechos humanos, que apunta a la demanda funcional y normativa de inclusión jurídica universal en condiciones de disenso, no depende de la mencionada institucionalización procedimental. No es una idea $a$ priori ${ }^{10}$, sino una construcción social de la sociedad moderna. La institucionalización procedimental de los derechos humanos está marcada por el pluralismo de las diversas interpretaciones de los mismos en diferentes contextos (Bobbio, 1992: 18 s.). En este sentido, a partir de las ideas de Rawls acerca de un "pluralismo racional" de interpretaciones divergentes (Rawls, 1993: $36 \mathrm{~s}$. y 144), Michelman habla de un "pluralismo interpretativo racional" de los derechos humanos (1999: 59 ss.). Esa expresión se relaciona, en rigor, con la propia variedad de concepciones en relación con el ámbito de validez normativa de los derechos humanos y con el problema de cómo enfrentar racionalmente tal variedad. Esto nos coloca, a su vez, ante la relación de los derechos humanos con la democracia. Michelman sostiene, con razón, que una interpretación correcta de los derechos humanos en un contexto político determinado depende de un discurso democrático abierto a la pluralidad de interpretaciones: "La razón por la cuál una persona sujeta a un determinado

\footnotetext{
${ }^{10}$ En sentido contrario, Michelman, 1999:53 s.
} 
régimen de derechos humanos puede, desde su convicción y lealtad, respetar ese régimen, sólo puede deberse al hecho de que la interpretación dominante de los derechos humanos en tal régimen está subordinada a un control y a una crítica democrática permanente" (1999: 61) ${ }^{11}$. No obstante, Michelman, siguiendo los pasos de Habermas, apunta a un discurso democrático guiado por el consenso (ibidem: 62). Como ya se observó anteriormente, la institucionalización de los derechos humanos, definidos como expectativas normativas orientadas a la inclusión jurídica en condiciones de disenso estructural, implica especialmente la construcción de procedimientos democráticos destinados a garantizar la convivencia social y política en esas condiciones de disenso estructural, no sólo absorbiendo éste, sino también estimulando su surgimiento. Esto significa que la institucionalización de los derechos humanos se relaciona con una base consensual de respeto a los procedimientos democráticos que, a su vez, asegura el disenso sobre el contenido de tales derechos (cf. Neves, 2000: 108 ss.). Ante la falta de procedimientos democráticos, aparece la tendencia a negar el disenso o reprimir su surgimiento y de excluir a ciertos grupos de la arena político-jurídica, de tal manera que la institucionalización de los derechos humanos en cuanto derechos de inclusión y de disenso resulta perjudicada. Es precisamente esta falta o fragilidad de los procedimientos democráticos en el ámbito de muchos Estados, y en el plano internacional o transnacional, lo que da lugar a hablar de la insuficiencia de la institucionalización de los derechos humanos. Aunque éstos no son un privilegio del Occidente desarrollado ${ }^{12}$, su institucionalización sólo se realizó de manera satisfactoria, en mayor o menor medida, y en las más diversas formas, en los ámbitos de los Estados de Derecho en los que los procedimientos democráticos alcanzaron un nivel de institucionalización y de realización socialmente relevante. Eso no significa, sin embargo, que sólo haya una posible lectura democrática de los derechos humanos. Las diferencias culturales y los tipos de orden jurídico (el estatal, internacional, transnacional, etc.) pueden llevar a institucionalizaciones democráticas bien diversas de los derechos humanos, dando énfasis a un aspecto (por ejemplo, el de los derechos individuales) o bien a otro (por ejemplo, el de los derechos sociales mínimos o de los derechos colectivos), pero, en todo caso,

\footnotetext{
${ }^{11}$ A partir de esta idea, Habermas (1992: 161 s.) subraya la afinidad y la "co-originalidad” de los derechos humanos y de la soberanía popular. En sentido contrario, vid. Böckenförde, 1999.

${ }^{12}$ Habermas (1998a: 170ss o 1999a) sostiene, con razón, que el problema de los derechos humnaos no puede ya ser entendido como un asunto particular de Occidente, y defiende "una interpretación de los derechos humanos que sea acorde con el mundo moderno también desde el punto de vista de otras culturas” (1998a: 181 s. o 1999a: 395).
} 
debe asegurarse la inclusión jurídica generalizada y el reconocimiento del disenso estructural.

En este sentido, puede darse relevancia a un tipo o a otro de derechos humanos. Así como T.H. Marshall (1976: 71 ss.; cf. también Bendix, 1969: 92 ss.; Neves, 1994b: 254 s.) se refería a diferentes fases en el desarrollo de la ciudadanía; a saber, la referida al surgimiento de los derechos civiles (libertad-autonomía individual), la referida al surgimiento de los derechos políticos (libertad-participación) y la relacionada con el advenimiento de los derechos sociales, apuntando a los conflictos que esas diversas formas de derechos involucraron, también es lugar común hacer referencia, análogamente, pero sin que coincida con aquellas fases, a las generaciones de derechos humanos correspondientes al surgimiento y desarrollo, respectivamente, de los derechos individuales, sociales y colectivos. Esa visión amplia de los derechos humanos, incluyendo los llamados derechos de tercera e incluso de cuarta generación (Lafer, 1988: 131 ss.), dio lugar a diversas críticas en relación con la vaguedad y también la inocuidad de tal concepto. En este sentido, Norberto Bobbio (1992: 6) se refiere al carácter excesivamente heterogéneo y vago de los derechos humanos de "tercera generación", "lo que nos impide comprender de qué se trata efectivamente"; y, apelando también a esa crítica, Danilo Zolo (1993: 259) objeta la "inflación normativa del concepto de ciudadanía" apuntando "el riesgo de disolución de su significado histórico y funcional”. También Luhmann (1993b: 574 ss.) adopta una semántica restrictiva cuando propone que la discusión sobre los derechos humanos desde la perspectiva de un sistema jurídico mundial se concentre en el problema de las ofensas flagrantes y escandalosas a la "dignidad humana". Así resultarían excluidos del ámbito de los derechos humanos pretensiones respecto de los “derechos sociales” mínimos, cuya realización o no estaría relacionada más bien con factores sociales y económicos extraños al Derecho, teniendo a la vista que tales derechos no serían susceptibles de institucionalización e implementación procesal en el plano de la sociedad mundial. Pero, así como la reacción a violaciones escandalosas y flagrantes de los derechos humanos como las que se ponen de manifiesto, por ejemplo, en la tortura y en el genocidio, constituye uno de los indicadores "más importantes del sistema jurídico mundial" (1993b: 578), no se puede negar que la falta de condiciones mínimas de supervivencia en las que se encuentra gran parte de la población en la sociedad mundial de hoy y que implica una exclusión social absoluta de los grupos humanos respectivos también se ha visto como violación enorme y escandalosa de la "dignidad humana" y, por lo tanto, de los derechos humanos en cuanto inclusión jurídica generalizada. En ambos casos, se trata de la paradoja de la declaración de expectativas normativas (contrafácticas) ante la propia práctica que, por comisión u omisión, los contradice sistemá- 
ticamente. La diferencia reside en el hecho de que los derechos humanos en sentido estricto, a saber, aquellos que se refieren básicamente a la prohibición de acciones violentas - políticas, policiales o militares- contra individuos o grupos son susceptibles de institucionalización y, sobre todo, cuentan con perspectivas de positivización e implementación procesal a escala mundial, especialmente siguiendo los pasos de las transformaciones en el Derecho internacional, mientras que los derechos sociales en gran parte llamados derechos humanos de tercera generación son frágilmente institucionalizados, y negativas las perspectivas de su positivización e implementación procesal en el contexto mundial. Estos últimos sólo fueron institucionalizados y positivizados en un ámbito muy restringido de algunos Estados Democráticos y Sociales de Derecho. La precariedad de su institucionalización y las dificultades de su implementación procesal permiten decir que se trata de derechos humanos frágiles, en contraposición a los derechos humanos fuertes, cuya positivización, al igual que su implementación procesal, se encuentran en el horizonte del mismo Derecho Internacional Público en calidad de ius cogens (Brunkhorst, 2002: 191 ss.). Sin duda, en los dos casos, se trata de expectativas que en el plano mundial precisamente se fortalecen, paradójicamente, con sus decepciones, y se sustentan en una fuerza predominantemente simbólica. Pero, considerado que los derechos humanos, definidos aquí como las expectativas normativas de inclusión jurídica generalizada en condiciones de disenso estructural de la sociedad mundial, están en la frontera del sistema jurídico, uniéndolo con una "moral de disenso" relativa a la autonomía de las esferas discursivas o sistémicas y a la inclusión social, se puede decir que ciertas formas de su expresión (derechos humanos frágiles) no cruzan todavía, para usar una metáfora, la puerta del sistema jurídico en el ámbito incluyente de la sociedad mundial, porque les falta un mínimo de institucionalización jurídica, de positivización y de condiciones de implementación procesal, mientras que otras formas (los derechos humanos fuertes) ya han cruzado esas fronteras y luchan, ahora ya especialmente, por su concretización y realización (v. Figura 3).

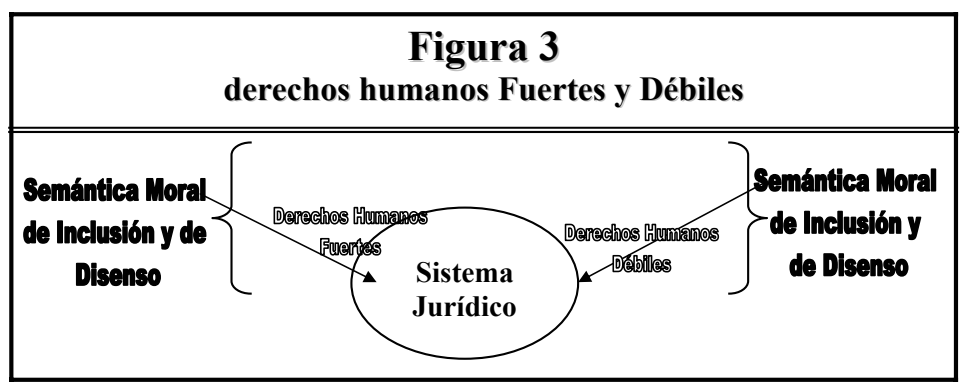


Como ya sugieren las anteriores observaciones, la construcción social de los derechos humanos tiene un carácter paradójico (¿qué construcción social no lo tiene?). En este sentido, Luhmann (1993a) da cuenta de la paradoja de los derechos humanos y de las tres formas de su desarrollo. En primer lugar, Luhmann señala la relación íntima entre la aparición de los derechos humanos individuales y la doctrina del contrato social original. La paradoja residiría en el problema acerca de qué viene primero, el contrato social o los individuos (ibídem: 541 ss.). La Teoría Contractualista habría buscado la superación de esa paradoja con la formulación según la cual los derechos humanos constituirían los derechos que "pueden pasar, a salvo, del estado de naturaleza al estado civil”, lo que implicaría, a su vez, la forma paradójica de los derechos humanos como unidades de la diferencia 'estado de naturaleza / estado civil’ (ibídem.: 542). Luhmann insiste, sin embargo, en que la paradoja que pretende eliminarse volvería de otra manera; a saber, con el problema de cómo el contrato, que sería vinculante por su misma fuerza, se adaptaría a las transformaciones de las relaciones sociales (ibídem). Pero esa evolución de la paradoja de los derechos humanos no tiene un interés directo en relación con el conjunto de problemas que se abordan en el ámbito de esta conferencia. Más importante aquí son las otras dos formas de evolución de la paradoja de los derechos humanos: aquella que se refiere a su positivización y la referida a su globalización. No se trata simplemente de los derechos humanos individuales, sino también de las otras formas de surgimiento de tales derechos humanos (como derechos sociales y de "tercera o cuarta generación”).

Las declaraciones políticas y, posteriormente, la positivización de los derechos humanos en las constituciones de los Estados democráticos de Derecho occidentales, que se remontan a las revoluciones liberales de fines del siglo XVIII, nos enfrentan a una nueva paradoja. Esta paradoja se pone de manifiesto en la pregunta sobre si los derechos humanos son derechos pre-positivos o si sólo tienen validez jurídica en la medida en que son positivizados. La "solución” a la paradoja habría sido hallada en la "plasmación en un texto, esto es, en la positivización de esos derechos pre-positivos" (Luhmann, 1993a: 542). Sin embargo, la paradoja aparecería nuevamente “en la forma de necesidad de positivización del Derecho pre-positivo” (ibídem). La forma de gestionar tal paradoja habría sido la formulación textual con el indicativo del verbo 'ser' (en vez del empleo de la forma deóntica 'deber-ser'), sea en las declaraciones políticas, sea en las constituciones, de tal manera que los derechos humanos pudieran ser considerados como los “derechos naturales” política y jurídicamente expresados y reconocidos textualmente (ibídem: 542 s.). Se podría ir más allá de Luhman y enfrentar la superación de la paradoja en el sentido de la distinción entre la semántica 
política y social de los derechos humanos y la semántica jurídico-positiva de los derechos fundamentales. En el ámbito del Estado Constitucional Democrático, las expectativas normativas referentes a la inclusión jurídica generalizada sólo obtienen validez jurídica si pasan la prueba de los procedimientos democráticos, constituyentes o constitucionales. Es verdad que la paradoja reaparece, una vez los derechos humanos se quedan en las fronteras del sistema jurídico, sea en la frontera externa, en cuanto que expectativas normativas que pretenden transformarse en normas jurídicas válidas por procedimientos positivizadores, sea en la frontera interna, como parte de los derechos fundamentales constitucionalmente garantizados (y, por tanto, en la cuestión de los derechos humanos, se pone de manifiesto, de manera señaladamente crucial, la paradoja de la apertura cognoscitiva fundada en el cierre operativo del sistema jurídico -Luhmann: 1983: el esp. 139 y 152 s., 1984: 110 ss.; 1993b: 38 ss.). Sin embargo, tal paradoja es socialmente visible, aunque no puede ser definitivamente superada, pues se relaciona con la diversidad de comprensiones de los propios derechos humanos como derechos a la inclusión jurídica generalizada en condiciones de disenso estructural. La forma de gestionar esa paradoja, en el Estado democrático de Derecho, fue la de girar hacia una positivización de los derechos humanos como derechos fundamentales dependientes de procedimientos constitucionales, al mismo tiempo selectivos en virtud de la pluralidad de expectativas normativas referentes a la inclusión jurídica generalizada y como derechos abiertos y promotores de esa misma pluralidad (y, así, resurge la paradoja de una nueva manera en forma de selección excluyente de lo incluido y de apertura incluyente de lo excluido).

La tercera forma de desarrollo de la paradoja de los derechos humanos se refiere a la pretensión de validarlos en el plano internacional o incluso en un Derecho mundial (Luhmann, 1993a: 543 ss., 1993b: 574 ss.). ${ }^{13}$ El problema está relacionado, sobre todo y más evidentemente, con el hecho reconocido de que muchos Estados no aceptan ni siquiera mínimamente los principios del Estado democrático de Derecho y se caracterizan por el rechazo directo de los derechos humanos mediante la exclusión jurídica de amplias porciones de la población (tendiendo incluso en ocasiones a la eliminación física), ya sea por razones étnico-culturales, políticas o económicas. En este caso, los propios textos jurídicos de jerarquía constitucional y legislativa rechazan cualquier idea de derechos humanos como derechos universales. Sin embargo, también en muchos Estados en los que los derechos humanos son constitucionalmente textualizados como derechos fundamentales, la

${ }^{13}$ Siguiendo los pasos de Luhman, aunque extrayendo otras consecuencias, cf. FischerLescano, 2002a, 2002b. 
Constitución carece de fuerza normativa sobremanera en el ámbito concreto de esos derechos, siendo ahí comunes las prácticas ilegales e inconstitucionales contrarias a los derechos humanos por parte de los propios órganos estatales. Finalmente, no se puede negar que, en muchas ocasiones, en los mismos Estados democráticos de Derecho que tienen una Constitución con amplia fuerza normativa resultante de procedimientos de concretización y realización normativo-constitucionales, existen prácticas de los agentes estatales contrarias a los derechos humanos constitucionalmente asegurados como derechos fundamentales que cristalizan en ciertos ámbitos de validez del orden jurídico. En este sentido, Luhmann señala que "la dimensión de las violaciones a los derechos humanos en casi todos los Estados es vergonzosa, al igual que lo drástico de los casos” (1993a: 543) y, a partir de esta constatación, define la nueva forma en que la paradoja de los derechos humanos se desarrolla en el contexto actual: "La validez de la norma se muestra en su violación” (1993a: 544). Es decir, la paradoja reside en el hecho que los derechos humanos son tanto más conocidos y afirmados cuanto más graves y frecuentes son las violaciones a los mismos. En este contexto, Luhmann limita los derechos humanos conceptualmente sólo a aquellas situaciones de violaciones escandalosas y especialmente vergonzosas a la dignidad humana en el ámbito de la sociedad mundial (1993b: 578 s.), sin ignorar el papel de los medios de comunicación en la construcción y control de los escándalos y en la provocación de la reacción correspondiente, muchas veces de forma selectivamente manipuladora (1993a: 545). Es verdad, sería de mal gusto, a la vista de las atrocidades de las ofensas violentas contra los derechos humanos, consultar los textos o investigar si son o no permitidas por el orden jurídico localmente válido (1993a: 544). Pero, por otro lado, es muy difícil determinar qué formas de violación de los derechos humanos deberían de caracterizarse como escandalosas y vergonzosas, convirtiendo, sólo por eso, las expectativas normativas correspondientes en normas válidas de un Derecho mundial. La percepción de lo que sea vergonzoso y escandaloso varía ampliamente en una situación de complejidad sistémica, pluralidad discursiva y heterogeneidad cultural de la sociedad mundial del presente (cf. Fischer-Lescano, 2002b: 363 ss.). Luhmann no ignora esa dificultad al enfatizar que "el orden jurídico mundial se asemeja más bien a formas de orden de sociedades tribales; o sea, precisa renunciar al poder sancionador organizado y a la definición auténtica de las violaciones a partir de reglas conocidas” (Luhmann, 1993a,: 544). De ahí que indague si no serían necesarias nuevas formas de “desarrollo” de la paradoja de los derechos humanos (ibídem).

Sin duda, el orden jurídico de una sociedad moderna muy compleja y rica en alternativas no puede ser adecuado a esa sociedad si mantiene las características de un orden jurídico tribal, apropiado a los límites de posibilidades 
de las sociedades arcaicas. Siendo así, cabe observar, que la paradoja de los derechos humanos sólo podrá ser superada de una manera productiva en la sociedad mundial actual mediante formas complejas de institucionalización de procedimientos en el ámbito global o internacional que, sin embargo, no pueden tener el carácter centralizado que marca la positivización de los derechos humanos como derechos fundamentales en la experiencia del Estado democrático de Derecho. Por tanto, aquí se exige, una vez más, pero de una manera innovadora, la urgencia de procedimientos que, además de actuar selectivamente ante la pluralidad de definiciones de las violaciones vergonzantes y escandalosas que implicarían la oportunidad de transformación de las expectativas normativas correspondientes a la norma jurídica válida, y con fuerza sancionadora referente a los derechos humanos (rule of law y due process of law), permanezcan abiertos (“democráticamente”) a esa misma pluralidad (y, también aquí, vuelve a ponerse de manifiesto la paradoja en forma de selección excluyente de lo incluido y de apertura incluyente de lo excluido). La inmensa dificultad de una tal institucionalización procedimental de los derechos humanos en el plano internacional o global da a la cuestión de su fuerza simbólica un realce aún más especial.

\section{IV}

Las anteriores tesis sobre la ambivalencia de la fuerza simbólica en la esfera normativa (II), sobre el sentido semántico-pragmático de los derechos humanos así como sobre las formas paradójicas de manifestación de su desarrollo a lo largo de la historia (III), abren camino a una mejor comprensión de la fuerza simbólica específica de los derechos humanos. Ante todo, la fuerza simbólica de los derechos humanos se muestra ambivalente. Por un lado, sirve a la fuerza normativo-jurídica y la realización de los mismos, por otro, sin embargo, contribuye a impedir o dificultar su concreción jurídica y su efectividad. Antes de adentrarnos en esa cuestión, me gustaría dar de nuevo una breve explicación sobre la relación entre la fuerza normativo-jurídica y la fuerza simbólica, ya que cuando se habla de la ambivalencia de la fuerza simbólica se trata en rigor de la ambivalencia de dicha relación.

La fuerza normativa de los derechos humanos se refiere, en primer lugar, a la concreción de las normas respectivas, sean constitucionales o legales en el ámbito de los Estados, sean jurídico-internacionales o jurídico-globales. La concreción, a su vez, concierne a la construcción del sentido de la norma jurídica a ser aplicada, judicial o extrajudicialmente, en un caso jurídico determinado (Müller, 1994, 1995: esp. 166 ss.). De la concreción en esa acepción técnica restringida cabe distinguir la realización en cuanto que 
eficacia y efectividad de la norma. ${ }^{14}$ La fuerza normativa envuelve tanto la concreción cuanto un cierto grado socialmente relevante de realización de la norma. La descaracterización del proceso concretizador con decisiones totalmente incompatibles con el sentido semántico-pragmático del texto normativo o, simplemente, la realización insuficiente (la ineficacia e inefectividad) de la norma significará que carezca de fuerza normativa. La fuerza simbólica, que se refiere al sentido connotativo, latente, en los respectivos textos o discursos normativos puede, como ya se afirmó anteriormente, contribuir a la intensificación de la fuerza normativa de los preceptos jurídicos. Pero la afirmación simbólica de textos normativos en el proceso constituyente o legislativo, en las convenciones y en los tratados internacionales o en otras formas de ordenación jurídica, así como en los discursos políticos, puede ir encaminada exactamente al encubrimiento de la insuficiente fuerza normativa de las respectivas instituciones jurídicas o incluso a perjudicarla. En lo que se refiere a los derechos humanos, la situación tiene algo de singular, puesto que su afirmación simbólica en el discurso jurídico-político es independiente de su plasmación en un texto. A pesar de ello, el discurso simbólico de los derechos humanos, que encierra fuertes tensiones, no actúa sólo en sentido negativo en relación con la fuerza normativa, sino que sirve también para incrementarla.

Las declaraciones liberales clásicas de derechos, en el contexto de la Revolución Francesa y del movimiento de independencia americana, contenían ya una fuerza simbólica que vino a contribuir en gran medida a la realización posterior de los derechos humanos. En ese sentido, Lefort se refiere a la relevancia de las declaraciones "legales" de los derechos humanos en el Estado Democrático de Derecho cuya función simbólica habría implicado la conquista y la ampliación de esos derechos (1981: 67 ss. y 82; trad. br., 1987: 56 ss. y 68). En ese sentido, puede observarse que el paso de la fuerza meramente simbólica a la fuerza normativa de los derechos humanos, con la conquista y extensión de los mismos, implicó cuatro momentos diferentes que, según el contexto histórico de construcción y desarrollo del respectivo Estado Democrático de Derecho, resultarán en procesos más lentos o más veloces.

En un primer momento, se manifiestan, en el ámbito de un discurso social difuso, amparado inicialmente en una reflexión filosófica (el contractualismo), expectativas normativas por inclusión universal en el Derecho. Estas expectativas implican, originariamente, una reacción contra el absolutismo

\footnotetext{
${ }^{14}$ En trabajos anteriores (1994a: 42ss., 1992: 83 ss.), adopté un sentido más amplio de concreción de la norma, abarcando tanto su concreción en el sentido técnico estricto como su realización.
} 
y la pretensión de afirmación política y validación jurídica de las libertades civiles (individuales). En ese contexto, se destacan sobre todo la libertad religiosa y la libertad económica (propiedad privada). La fuerza simbólica de este discurso social, fuertemente conflictualista, conduce posteriormente a la estructuración política de las expectativas correspondientes. En ese segundo momento aparecen las declaraciones políticas de las libertades civiles, sin que éstas tengan la validez jurídica de los derechos positivizados. Aquí hay ya un fuerte grado de selectividad en relación con las expectativas diversas y en conflicto que surgen en el momento anterior. Las declaraciones políticas de las libertades civiles tuvieron una enorme fuerza simbólica en los procesos constituyentes surgidos de las revoluciones liberales. Tal fuerza simbólica contribuyó enormemente a la positivación jurídica de esas libertades como derechos constitucionalmente garantizados. Pero, en ese tercer momento, se llega, en rigor, sólo a la plasmación en un texto de expectativas normativas referidas a las libertades individuales. Evidentemente, la fuerza normativa no surge directamente de la textualización en documentos constitucionales. Ésta implica ciertamente una estructuración jurídica selectiva de expectativas normativas plasmadas en el texto de las declaraciones políticas. Sin embargo, los textos de normas, y sobre todo de normas constitucionales, pueden aparecer de forma abundante, sin que éstas sean materializadas o realizadas. La plasmación textual de una constitución puede, en cambio, jugar un papel simbólico relevante en la progresiva concreción y realización normativa. Es sólo en este cuarto momento cuando se pasa de una fuerza meramente simbólica a una fuerza normativo-jurídica de los derechos humanos en tanto que derechos constitucionales concretados y ampliamente realizados en el Estado Democrático de Derecho. Aquí hay una especie de equilibrio constructivo entre la fuerza simbólica y la fuerza normativa, una sirviendo de apoyo y fortificando recíprocamente a la otra.

Estas tomas de posición sobre los momentos de afirmación simbólica de los derechos humanos en la dirección de su ulterior fuerza normativa no deben llevar a entender que se trata de un proceso lineal. También en el Estado Democrático de Derecho occidental hubo avances y retrocesos en la institucionalización de los derechos humanos individuales. Su cuestionamiento en el ámbito de los movimientos socialistas, la negación político-jurídica de los mismos en las experiencias totalitarias del siglo XX, así como su vulneración en la práctica de los agentes estatales y los límites en su realización por falta de presupuestos sociales y económicos, son todos ellos hechos que indiscutiblemente bloquean su desenvolvimiento. Por otra parte, el surgimiento de nuevas expectativas normativas referentes al encuadramiento de los derechos políticos, sociales y “de tercera o cuarta generación” en la esfera de los derechos humanos, ha traído consigo nuevos conflictos relacio- 
nados con la tensión entre las pretensiones respectivamente contenidas en esos tipos de derechos. A su vez, estos nuevos derechos necesitaron también pasar por aquellos cuatro momentos de transición desde la fuerza meramente simbólica a su fuerza normativa plena. Es así como se produce una suerte de intersección no coincidente de momentos: unas veces, por ejemplo, ciertos derechos sociales sin ningún tipo de fuerza normativo-jurídica llegan a ser, con una fuerza simbólica mayor o menor, socialmente reivindicados o políticamente declarados, o bien plasmados textualmente en documentos constitucionales determinados, precisamente en el sentido de una limitación de los derechos humanos referidos a las libertades económicas individuales, tales como el derecho de propiedad y la libertad contractual que se caracterizan por gozar de plena fuerza normativa en los términos de la Constitución normativa. De la misma manera, no puede negarse que la pretensión de las minorías étnicas en pro del respeto a su identidad, que se quiere enmarcar en los derechos culturales de "tercera generación", ha tenido, incluso en Estados democráticos de Derecho de Europa y de América del Norte, y aun cuando no dispusiera de fuerza normativa alguna, una fuerza simbólica perturbadora de los derechos humanos individuales clásicos, estos sí, con amplia fuerza normativa en el régimen constitucional de las democracias occidentales.

Asimismo, la fuerza simbólica positiva de los derechos humanos en el sentido de su institucionalización con fuerza normativa sólo prevalece en los Estados Constitucionales y Democráticos occidentales, que constituyen una porción muy reducida del grupo de los llamados “Estados Nacionales”. En palabras de Loewenstein (1975: 151 ss.), la concreción normativa y la realización fáctica de los derechos humanos como derechos fundamentales sólo se impuso de forma adecuada en el contexto de las "constituciones normativas”. En las llamadas “constituciones nominalistas” y "semánticas” falta a las disposiciones referentes a los derechos humanos fuerza normativa jurídica y socialmente relevante. El problema reside en el hecho de que aunque los derechos humanos como construcción y conquista histórica de la modernidad han surgido con el constitucionalismo liberal occidental, la exigencia de su concreción normativa y de su realización fáctica no es ya sólo un asunto privativo de Occidente, sino que se ha vuelto, cada vez más, un problema que se presenta en los más diversos Estados y en los más variados contextos nacionales (vid. supra nota 11). No se trata aquí de encontrar una salida simplista y afirmar que la plasmación textual de los derechos humanos en los documentos constitucionales o legales de los Estados periféricos o de aquellos que no comparten los valores occidentales constituye simplemente una copia colonizada e inadecuada de los modelos de los países dominantes. Aunque las concepciones de los derechos humanos varían, la idea 
de inclusión jurídica generalizada en condiciones de disenso estructural de la sociedad mundial emerge problemáticamente, y de forma relevante, en todas las partes del globo terrestre. Este problema es previo al de enfrentar las variables socio-económicas, políticas y culturales que dificultan o impiden la concreción normativa y la realización fáctica de los derechos humanos en la mayoría de los Estados y que conducen, con frecuencia, a una hipertrofia de su fuerza simbólica en detrimento de su fuerza normativa.

En el ámbito de las "constituciones nominalistas", los derechos humanos pasan por tres de los cuatro momentos mencionados más arriba orientados a su institucionalización con fuerza normativa, llegando a ser plasmados textualmente en los respectivos documentos constitucionales de forma amplia y con precisión. Tal textualización tiene, sin embargo, una función eminentemente simbólica y no contribuye de un modo relevante a la fuerza normativa de los derechos humanos. Las normas constitucionales que se refieren a los derechos humanos son sistemáticamente bloqueadas en el curso del proceso de concreción normativa y, por consiguiente, son ampliamente carentes de eficacia. La exclusión social de una gran parte de la población impide la inclusión jurídica generalizada y, con ello, los derechos humanos se tornan, paradójicamente, un privilegio de minorías. La textualización de los derechos humanos desempeña el importante papel político-simbólico de presentar al Estado o al gobierno como instancia identificada con las expectativas normativas expresadas en las correspondientes disposiciones constitucionales. Como ya apunté más arriba, he discutido este asunto de manera más abarcante, no sólo en relación con los derechos humanos, en mi trabajo titulado A Constitucionalização simbólica (Neves, 1994a). Pero principalmente en relación con los derechos humanos puede decirse que, en los casos de constitucionalización simbólica, el Derecho es "superexplotado" por la política (cf. ibidem: 132). Como lo expresa la fórmula paradójica de Raymundo Faoro, en su brillante análisis del constitucionalismo de fachada en Brasil, se trata, en el contexto de la constitucionalización simbólica de los derechos humanos en general, de la "creación de un mundo falso más eficiente que el mundo verdadero” (Faoro, 1976: 175). Se crea así la ilusión de los "derechos humanos" constitucionalmente consagrados y se obstruye, al mismo tiempo, una discusión consecuente de los factores que impiden su concreción normativa. Así, la plasmación en un texto de los derechos humanos, aunque también puede cumplir las funciones de "confirmación de valores" de determinado grupo o de "compromiso dilatorio", típicas de la legislación simbólica en general, desempeña sobre todo una función de coartada (Neves, 1994a: 34 ss. y 92 ss.; Kindermann, 1988, 1989). Sin embargo, la hipertrofia de la fuerza simbólica de los derechos humanos en detrimento de su fuerza normativa, en el ámbito del constitucionalismo simbólico, no 
sólo puede originar la apatía y la desconfianza del público en relación con el Estado y sus agentes, sino también conducir, tanto por parte de la llamada "sociedad civil" como de la oposición política organizada, contraria al status quo, a un discurso crítico con la insuficiente concreción de los mismos apoyándose en la referencia a su propia textualización constitucional. En esa perspectiva, la fuerza simbólica de los textos y discursos constitucionales referidos a los derechos humanos puede llegar a cobrar una dimensión positiva en el sentido de promover la concreción y la realización de las normas correspondientes en los propios casos de constituciones "nominales" o “simbólicas” (aunque, con frecuencia, la postura “crítica” de las oposiciones puede constituir también nada más que una escenificación política sin consecuencias prácticas en relación con la fuerza normativa de los derechos humanos o, tomando éstos en serio, tropezar con límites estructurales difíciles de superar en el respectivo contexto social). Innegablemente, en tales casos, el aspecto positivo que pueda ejercer la fuerza simbólica para promover la fuerza normativa es claramente más limitado de lo que sucede en el contexto de las “constituciones normativas”. Ahora bien, tampoco en el ámbito de la constitucionalización simbólica desaparece el carácter ambivalente que la fuerza simbólica de los derechos humanos tiene en relación con su fuerza normativa, ya sea impidiéndola o dificultándola, ya sea promoviéndola; sólo que la balanza, al contrario de lo que ocurre con las "constituciones normativas”, se inclina más bien, con fuerza, del lado negativo.

Ya en relación con las “constituciones semánticas”, a las que prefiero denominar "constituciones instrumentales" pues constituyen meros instrumentos de los detentadores eventuales del poder (Neves, 1994: 98 s., 1992: 69ss), siendo alteradas a merced de sus necesidades e intereses concretos para mantener el poder, no puede hablarse de una función predominantemente simbólica mediante la textualización de los derechos humanos. En esa hipótesis, que corresponde a las experiencias políticas autocráticas, sean totalitarias o autoritarias (Loewenstein, 1975: 52 ss.), ya en el plano de las leyes con fuerza constitucional, los derechos humanos son rechazados directa, abierta y ampliamente o bien textualizados con tantas restricciones que pierden cualquier significado práctico. No sólo a partir del proceso bloqueado de concreción constitucional, sino ya a partir de los propios textos con jerarquía constitucional, puede inferirse que se trata de un régimen de negación de los derechos humanos. Ello no significa que en el ámbito de las experiencias autocráticas, caracterizadas más bien por una instrumentalización de la legislación de rango constitucional, no se haga uso de la fuerza simbólica de los derechos humanos. Esto sucede más comúnmente en el discurso político, al margen de cualquier tipo de textualización jurídica, si bien puede haber formas de plasmación en documentos constitucionales o 
legales. Asi, por ejemplo, la Constitución brasileña de 1967, en la redacción dada por la Enmienda $\mathrm{N}^{\circ} 1$ de 1969, que entró en vigor en el auge del régimen militar autoritario (1964-1984), mantenía la referencia a los derechos individuales fundamentales y sus garantías (arts. 153-154). Aunque el Acto Institucional $\mathrm{N}^{\circ} 5$, de 1968, con fuerza normativa (supra)constitucional (¿“la verdadera Constitución jurídica” del régimen militar?), otorgara al jefe del poder Ejecutivo la competencia para suspender las garantías constitucionales, ${ }^{15}$ no se puede negar que tal textualización constitucional desempeñaba la función simbólica de presentar al régimen como identificado con los derechos humanos individuales negados por el totalitarismo de izquierdas, contra el cual, pretendidamente, la dictadura había venido a luchar. La utilizacion negativa de la fuerza simbólica de los derechos humanos, que servía especialmente para la presentación internacional del Estado como "relativamente democrático", llevó a la reglamentación del Conselho de Defesa dos Direitos da Pessoa Humana (Reglamento Interno aprobado por el Decreto $\mathrm{N}^{\circ}$. 63.681, de 22/11/68), que había sido creado por la Ley $\mathrm{N}^{\circ}$. 4.319, de 16/03/64, promulgada por el régimen depuesto en $1964 \mathrm{y}$ posteriormente modificada por la Ley 5.763, de 15/12/71, que aseguraba la mayoría gubernamental (cf. Neves, 1972). El papel simbólico de coartada desempeñado por ese Consejo residía en el hecho de que la mayoría gubernamental siempre prevalecía en contra de la minoría formada por los representantes de la oposición tolerada y por los representantes de la sociedad civil, de tal manera que todos los casos graves y escandalosos de violación de los derechos humanos en los que estaban implicados agentes del Estado o del gobierno eran archivados. El Consejo era un consejo de fachada que servía exactamente para obstaculizar un régimen de derechos humanos. Pero no por ello desapareció en el ámbito de las oposiciones legales e ilegales y de la "sociedad civil" organizada (e inclusive en la voz altiva y valiente del representante de la $\mathrm{OAB}$ en el Consejo, protestando contra el archivo de los procesos y denunciando su farsa), y a pesar de toda la represión, la fuerza simbólica de los derechos humanos en el sentido positivo de su textualización constitucional y su fuerza normativa amplia e irrestricta. También en aquellas condiciones había una ambivalencia de la fuerza simbólica de los derechos humanos, aunque la balanza cayese del lado negativo en relación con su fuerza normativa. Aun así, en el "constitucionalismo semántico", especialmente en las experiencias totalitarias, la negación directa y abierta

\footnotetext{
${ }^{15}$ A partir de la formulación en forma de paradoja que hace Luhmann en relación con mis interpretaciones del caso brasileño (Neves, 1992, 1994) se puede afirmar que en un contexto semejante "se gobierna inconstitucionalmente con ayuda de la Constitución" (Luhmann, 2000: 428).
} 
de los derechos humanos por el régimen, incluso en la legislación (es el caso chocante de la legislacion racista y genocida del nacionalsocialismo en Alemania), implica que la fuerza simbólica de los derechos humanos sólo puede manifestarse en su forma positiva en el contexto de la lucha contra el propio régimen violador de los derechos humanos.

Para concluir estas afirmaciones acerca de la fuerza simbólica ambivalente de los derechos humanos en el plano estatal, me gustaría llamar la atención sobre un ejemplo interesante que concierne al caso híbrido de constitución "nominalista” y "semántica" que caracteriza al actual régimen venezolano del presidente Hugo Chávez. El art. 350 de la Constitución venezolana de 1999, dictado en conformidad con la pretensión gubernamental de justificar a posteriori la tentativa de golpe de Estado dirigida por Chávez en 1992, establece: "El pueblo de Venezuela [...] desconocerá cualquier régimen, legislación o autoridad que contrarí los valores, principios y garantías democráticos o menoscabe los derechos humanos.” Tal disposición, que justificaría la desobediencia civil, fue recientemente invocada por el General Enrique Medina Gómez, líder de un grupo de oficiales rebeldes, justamente para convocar a los venezolanos a la desobediencia contra el régimen del presidente Chávez (Delcas, 2002). Con tal ejemplo, se demuestra, de forma contundente, que la fuerza simbólica de los derechos humanos puede ser utilizada en los más diversos sentidos, incluso para justificar retóricamente golpes de Estado y rebeliones militares.

\section{V}

Más recientemente, la cuestión de la fuerza simbólica de los derechos humanos ha adquirido un significado particular en el campo del Derecho Internacional público o de un Derecho mundial emergente. En este nuevo contexto, se discute principalmente si y en qué medida el orden jurídico internacional o transnacional faculta normativamente el control y sanción de los Estados que violen directamente los derechos humanos o no estén en condiciones de protegerlos. Se destaca en primer plano el problema de la legitimidad o no de la intervencion para proteger los derechos humanos.

En el ámbito internacional, puede observarse que ha habido el desarrollo de una semántica socialmente difusa, pasando por un momento de declaraciones de naturaleza eminentemente política ${ }^{16}$ hasta la textualiza-

\footnotetext{
${ }^{16}$ La propia Declaración Universal de derechos Humanos (1948) se presentó en su origen como mera "recomendación” política de la Asamblea General de Naciones Unidas a sus miembros, sin pretensión de vinculatoriedad jurídica. Sólo más tarde fue interpretada como texto normativo de Derecho Internacional Público, especialmente en el ámbito de Jurisprudencia de la Corte Internacional de Justicia (cf. Comparato, 1999: 209-211).
} 
ción jurídico-internacional de los derechos humanos en convenciones y tratados. Además, puede observarse un proceso de evolución que va desde la protección de los derechos humanos específicos ${ }^{17}$ hacia un régimen de protección generalizada que se inicia con la Carta de Naciones Unidas. Posteriormente, surgen las convenciones o cartas regionales (Convención Europea, Convención Americana, Carta Africana etc.). ${ }^{18}$ Sin embargo, pese a tal intensa evolución en el plano de los textos normativos, los derechos humanos permanecen con una fuerza predominantemente simbólica en el Derecho Internacional. La concreción y la realización de las normas internacionales referentes a la protección de los derechos humanos son muy limitadas. Aquello que Habermas (1999b: 229) acertadamente sostiene en relación con la constitucionalización simbólica que he analizado, a saber, que en esas circunstancias, "la letra inmaculada del texto constitucional no es sino la fachada simbólica de un orden jurídico impuesto de una manera altamente selectiva”, puede ser afirmado, a pesar de la diversidad de estructuras y contextos, en relación con el régimen jurídico internacional de los derechos humanos. Incluso admitiéndose la existencia de una Constitución de la "comunidad internacional" (Fassbender, 1998), que estaría estrechamente relacionada con la protección global de los derechos humanos, no se puede negar que esa Constitución tendría características análogas a las de las constituciones simbólicas en la esfera estatal: hipertrofia de su función simbólica en detrimento de su fuerza normativa (cf. Fischer-Lescano, 2002a: 1244). El problema concierne, en primer lugar, a la dificultad de determinar la competencia orgánica, el domínio material y la capacidad para una protección generalizada de los derechos humanos, en los términos de reglas y procedimientos preestablecidos (rule of law y due process of law): ¿Quién es competente para decidir e implementar la protección de los derechos humanos contra los Estados u organizaciones que los violan sistemáticamente? ¿Qué casos traen aparejado el control y justifican las sanciones? ¿Existen los presupuestos e instrumentos que hacen posible una protección generalizada? En segundo lugar, el problema se refiere al uso político de la retórica de los derechos humanos a los fines de imposición de intereses de determinadas potencias: aquí cabría hablar, un tanto paradójicamente, de "imperialismo de los derechos humanos".

\footnotetext{
${ }^{17}$ Estoy pensando aquí, de forma muy general, también en el llamado "Derecho humanitario" consagrado en las Convenciones de Ginebra de 1864 y 1929 (aunque se diferencie técnico-jurídicamente de los derechos humanos: cf. Provost, 2002: esp. 6 ss.) y sobre todo en la Convención de Ginebra sobre Esclavitud (1926).

${ }^{18}$ Sobre el desarrollo de la protección internacional de los Derechos Humanos en las convenciones, tratados y cartas, v., por ej., Comparato, 1999; Piovesan, 1996; Lafer, 1999: 147 ss.
} 
La determinación del (de los) órgano(s) competente(s) para definir los casos que implican violaciones de los derechos humanos e implementar una protección generalizada de los mismos envuelve problemas de naturaleza jurídico-dogmática, de legitimidad y de condiciones prácticas, que se implican mutuamente. Aquí nos interesa especialmente el problema de la intervención militar para la protección de los derechos humanos. Desde una perspectiva jurídico-dogmática, nos enfrentamos con algunas dificultades entre las que destaca la vaguedad de la noción de amenaza a la "paz y seguridad internacional” que deben ser mantenidas conforme a las resoluciones del Consejo de Seguridad de la ONU (Art. 39 de la Carta de ONU), noción que ha dado ocasión a una práctica intervencionista, así como la relación conflictiva entre las garantías de los derechos humanos, proclamadas en los artículos 1.3. y 55-56 de la Carta de la ONU, y el principio de no intervención, consagrado en el art. 2.7, relación que se vuelve más problemática cuando se considera el principio de "autodeterminación de los pueblos", previsto en el art. 1.2. El concepto extremadamente vago de amenaza a la paz y a la seguridad vino en la práctica a constituirse en una autorización en blanco al Consejo de Seguridad en su actividad intervencionista (Koskenniemi, 1998: 64). Y la relación entre las garantías de los derechos humanos y el principio de no-intervención "sólo es determinable a partir de la práctica aplicadora de los órganos políticos de la ONU, de acuerdo con las prioridades válidas en el momento” (ibidem: 65). Tal situación nos conduce al problema de la legitimidad del propio Consejo de Seguridad -en cuyo funcionamiento el principio de derecho de veto de los cinco miembros permanentes (art. 27.3) desempeña un papel decisivo- para proceder a una protección generalizada de los derechos humanos. Hay una especie de hiperpolitización de la protección internacional que, de forma casuística, no corresponde a las exigencias de un modelo jurídico generalizado en terminos de "rule of law". En este contexto, el Derecho permanece subordinado directamente al poder. Las propias competencias de la Corte Internacional de Justicia han sido desconocidas por el Consejo de Seguridad, sin que ello haya implicado sanción alguna (cf. ibidem: 63 s.). De esta manera, el Consejo de Seguridad "lleva a cabo un intervencionismo arbitrario” en relación con los derechos humanos (Brunkhorst, 1999: 382), lo que supone "intenciones paternalistas” inherentes a las propuestas intervencionistas y la clasificación "selectiva” de las violaciones de los derechos humanos que traen aparejadas la intervención (Maus, 1997: 168 e 190).

De ahí la razón de que permanezca muy limitada la fuerza normativajurídica de la protección internacional de los derechos humanos. En el plano internacional se desarrolla una práctica de relación entre poder y Derecho que conserva, al mismo tiempo, trazos de las constituciones "nominalistas" 
o simbólicas y de las constituciones "semánticas" o instrumentalistas del ámbito de los Estados. De un lado, la función predominantemente simbólica es expresada sobre todo en la Declaración Universal de los derechos Humanos y en las garantías contenidas en la Carta de las Naciones Unidas. Por otro lado, la falta de un modelo de "separación de poderes", con una prevalencia prácticamente absoluta del Consejo de Seguridad en relación con la Corte Internacional de Justicia y la Asamblea General de la ONU, trae consigo una instrumentalización de los propios textos normativos por aquel órgano ejecutivo-militar, que también desempeña funciones de naturaleza "cuasi-legislativa” (resoluciones) y judiciales (enjuiciamiento de los casos de violación de los derechos humanos, p. ej.). Pero incluso en esa estructura asimétrica de poder, la fuerza simbólica de los derechos humanos está presente. De un lado, el Consejo de Seguridad, órgano que expresa los intereses de una minoría, recurre al discurso de los derechos humanos principalmente para justificar su práctica intervencionista en relación con los Estados más débiles en la constelación internacional de poder. Obviamente, este uso de la fuerza simbólica tiene un carácter manipulador y afecta negativamente al incremento de la fuerza normativa de los derechos humanos. De otro lado, no puede negarse que la Asamblea General, en su debilidad político-real, ha realizado, en parte, una política simbólica que favorece una evolución en la dirección de la fuerza normativa de los derechos humanos. En el mismo sentido ha actuado la llamada "frágil esfera pública global" (Brunkhorst, 2002: 184 ss.), formada principalmente por organizaciones no gubernamentales y movimientos sociales, así como "los sectores espontáneos" (Teubner, 2000, 2003: 25 s.) de la Sociedad mundial. En suma, hay también una ambivalencia de la fuerza simbólica de los derechos humanos en lo que concierne a su concreción normativa y realización en el plano internacional o global: la textualización en la Carta de la ONU y en diversos tratados, convenciones y declaraciones, así como el discurso de la Asamblea General y de la "frágil esfera pública global” tiene, sobre todo, una fuerza simbólica positiva, mientras que la práctica política arbitraria del Consejo de Seguridad y de las grandes potencias mundiales se vincula principalmente a un uso negativo de la fuerza simbólica de los derechos humanos, algo que no sólo encubre el juego de intereses que con frecuencia está en la base del intervencionismo, sino que también implica muchas veces violaciones escandalosas de los derechos humanos.

\section{VI}

El problema se agrava cuando tenemos en cuenta la nueva postura de los Estados Unidos de América y de su instrumento, la OTAN que, desde la caída del bloque sovietico, viene desarrollando, cada vez más, una política 
intervencionista en nombre tanto de la "paz y la seguridad internacional" como de los derechos humanos, sin autorización del Consejo de Seguridad de la ONU, tendencia que se acentuó con el gobierno Bush y especialmente con el atentado terrorista del 11 de septiembre de 2001 en Nueva York. Es algo incontestable que el Consejo es un órgano sin ninguna estructura democrática y que ya venía actuando arbitrariamente; pero el hecho de que se le atribuyera la competencia para decidir sobre la intervención implicaba un mínimo de juridicidad subyacente y podía abrir nuevos desarrollos y reformas en el ámbito de la ONU, fuera en el sentido de una reestructuración, apertura y control democráticos del Consejo, fuera en el sentido de una fortificación de la Asamblea General y de la Corte Internacional de Justicia. Sin embargo, el modelo de intervencionismo unilateral, que viene siendo ordenado por el gobierno americano, sin tener en cuenta al propio Consejo, apunta en otra dirección. La ONU pierde en ese contexto su significado y la única superpotencia del mundo asume la posicion de "policía” del mundo. Tal "policía”, sin embargo, se ha demostrado enormemente selectiva y arbitraria, manteniendo la pretensión de no subordinarse a los propios procedimientos de control de las violaciones de los derechos humanos en el plano del Derecho Internacional Público. Aunque sea indiscutible que "sería insoportable abandonar el sistema jurídico al arbitrio de procesos políticos regionales” (Luhmann, 1993b: 577) -basta pensar en la experiencia del Nacionalsocialismo-, también se vuelve cada vez más inaceptable que los Estados Unidos de América (o cualquier otro Estado) "se presenten como juez y poder sancionador” (ibidem: 580). Tal unilateralismo tiene mucho más que ver con el mantenimiento de la hegemonía política que con una pretensión generalizada de dar fuerza normativa a los derechos humanos. ${ }^{19}$ Se recurre en este contexto de forma abusiva y manipulativa al discurso de los derechos humanos. No faltan voces dispuestas a argumentar en nombre de la "razón" en favor de la práctica intervencionista unilateral de los Estados Unidos y de su instrumento, la OTAN.

Es así como Jürgen Habermas, habiéndose pronunciado anteriormente con claridad en favor de la legitimación procedimental de la "intervención humanitaria” en el ámbito de una "política interna mundial” que implicaría reformas profundas y amplias de la ONU (Habermas, 1996: 225 s.), ${ }^{20}$ se pronunció, sin negar su anterior posición (2000: 60), de forma contradicto-

${ }^{19}$ A este respecto, cabe levantar "la sospecha de que también los derechos humanos sirven de pretexto para intervenir en relaciones políticas que sólo pueden ser resueltas responsablemente -sea democráticamente o no- en el plano nacional” (Luhmann, 1999:253).

${ }^{20}$ Tal "politica interna mundial” [Weltinnenpolitik], distinta de "un federalismo de Estados libres” (Kant, 1993: 208) o de "una república federal y subsidiaria mundial” (Höffe, 2002a: 225 ss., 2002b), sería capaz de explotar las instituciones y los procedimientos necesarios para 
ria, en nombre del universalismo moral de los derechos humanos, en favor de la legitimidad de la intervención de la OTAN en Yugoslavia con ocasión del conflicto de Kosovo, en 1999, con una única restricción: "La auto-autorización de la OTAN no debe convertirse en el caso-regla" (2000: 65). De acuerdo con esa comprensión del carácter "moral" y "racional" de la "intervención humanitaria" puesta en práctica, unilateralmente, por las grandes potencias occidentales, la propuesta de Habermas no apunta hacia una "política interna mundial" para la imposición de los derechos humanos, sino más bien hacia una política externa de Occidente para la vigilancia de las políticas de "derechos humanos" de los países más débiles en las relaciones internacionales de poder (Neves, 2000: 206 s., 2002: 347). ${ }^{21}$ De este modo, con la "moralización" simbólica de los derechos humanos, las decisiones y ejecuciones selectivas y arbitrarias de la intervención no son susceptibles de control mediante procedimientos en conformidad con el modelo de rule of law y due process of law. En consecuencia, sin límites o controles jurídicos, un intervencionismo de ese tipo, implicando como implica un poder sobre el Derecho, tiende a proceder impunemente contra los propios derechos humanos.

En Estados Unidos también voces del main stream se han manifestado en contra de tal práctica política norteamericana. Así, por ejemplo, Joseph Nye puso en cuestión el "hard power" que se expresa en el uso de la fuerza militar por los EUA, al defender la tesis de que sería más importante para la garantía y ampliación del liderazgo estadounidense en el mundo el "soft power" que se expresa en la difusión de la cultura política americana (1991: esp. 188 ss., 2002: esp. 75). En ese sentido, una política orientada a atraer a otros Estados y naciones para que se adhieran a los valores liberales y democráticos de los Estados Unidos sería más eficaz para el mantenimiento del liderazgo americano que el uso de la fuerza militar. Si esto es así, la dimensión de lo simbólico estaría en un primer plano y, aparentemente, contribuiría a la realización de los derechos humanos. Sin embargo, un modelo como el mencionado se corresponde más bien con una imposición

la construcción de intereses comunes en términos de una ciudadanía mundial (Habermas, 1998b:79s.). Al respecto, véase críticamente Neves, 2000:201ss.

${ }^{21}$ Más recientemente, en relación con la invasión de Iraq por las tropas norteamericanas, Habermas (2003) adopta una actitud diferente, al criticar la pretensión de "unilateralismo hegemónico" de los Estados Unidos de América, considerando que es contraria al "núcleo universalista de la democracia y de los derechos humanos”. Sin embargo, no rechaza su posición relativa al conflicto de Kosovo, antes bien la reitera justificando igualmente un cierto 'intervencionismo racional', 'moralmente fundado', aun sin la aprobación por los procedimientos jurídicos del Derecho Internacional Público (cf. también Habermas, 2004, donde se manifesta también con reservas en relación con la intervención en Afganistan). Con una postura un tanto diferente, cf. Arato/Brunkhorst, 2003. 
de los valores orientada a asegurarse la hegemonía política, teniendo muy poco que ver con la globalización de la fuerza normativa de los derechos humanos. La diversidad de concepciones de los derechos humanos, definidos aquí como expectativas normativas de inclusión jurídica generalizada en las condiciones de disenso estructural de la sociedad mundial, es incompatible con la imposición de una lectura única de su contenido, incluyendo aquella que prevalece en los Estados Unidos. La institucionalización de los derechos humanos en el plano internacional o global exige procedimentos selectivos y abiertos a diversas perspectivas, dependiendo a su vez, sin embargo, de una base consensual a propósito de esos procedimientos intermediadores de los disensos. La pretensión de imponer una única cultura política, sea por medio de hard o soft power, es contraria, por lo tanto, a una política consecuente de protección de los derechos humanos como derechos a la inclusión y derechos al disenso.

Puede observarse que viene desenvolviéndose un "imperialismo de los derechos humanos” en la discusión académica internacional. Este “imperialismo” no sólo constitutye un reclamo estratégico o ideológico de aseguramiento de la hegemonía política (en el sentido de Nye), sino que también recurre a la "moral” y a la "razón” (como Habermas). El peligro del recurso a la "moral” y a la "razón”, sin procedimentalización jurídica, consiste en el hecho de que la falta de límites jurídicos puede llevar a abusos incontrolables y, por tanto, a la impunidad de los más fuertes. A este respecto, puede afirmarse, tal como en otro contexto lo ha hecho el internacionalista Martti Koskenniemi, que "el imperialismo racional se revela como una fachada para el imperialismo cínico” (2002: 500). En otras palabras, cabría afirmar que todo intento por imponer unilateralmente la "razón moral” de los derechos humanos puede tener resultados destructivos para la "razón jurídica” de los mismos. Sin querer negar aquí su fundamento moral, me parece que, en ausencia de una institucionalización jurídica de los derechos humanos a través de procedimientos consistentemente selectivos y adecuadamente abiertos a las más diversas interpretaciones, pueden transformarse, bajo el dominio del intervencionismo unilateral de los Estados Unidos de América y de la OTAN, en una figura de retórica político-militar, cuya fuerza simbólica dificulta u obstaculiza su fuerza normativa. Lo anterior no significa que sea irrelevante la fuerza simbólica de los discursos contrarios a las violaciones vergonzosas y escandalosas de los derechos humanos por medio del intervencionismo: ella surge como contrapoder simbólico en el sentido de una mayor fuerza normativa de los derechos humanos en el plano internacional y mundial. En ese contexto de violaciones sistemáticas de los derechos humanos por sus supuestos protectores, el carácter ambivalente de su fuerza simbólica se acentúa aún más, y de ahí que lo escandaloso de las 
violaciones fortalezca las expectativas normativas contrarias, haciendo cada vez más necesarias las protestas. Aunque las condiciones estructurales todavía sean muy incipientes, se impone la superación de esa paradoja mediante la conquista de un mínimo de equilibrio entre la fuerza simbólica y la fuerza normativa de los derechos humanos. Eso implica la aparición de nuevas formas de desarrollo y procesamiento de la paradoja de los derechos humanos, exigiendo, por un lado, la institucionalización de la protección internacional o global de los mismos por procedimientos democráticos y, por otro, la ampliación del modelo de Estado democrático de Derecho en diversos contextos culturales de la sociedad mundial del presente. Ya se han convertido en lugares comunes las demandas en pro de la institucionalización "democrática” de los derechos humanos a la luz del rule of law y del due process of law en el plano internacional y transnacional, del fortalecimiento de la “división de poderes” en la ONU, de tribunales competentes independientes de los Estados para las cuestiones de derechos humanos, y de una mayor influencia de los "sectores espontáneos" sobre los “sectores organizados” de la sociedad mundial. Los desarrollos en tal sentido - que se constituyen cada vez más en pretensiones y esperanzas, pero aún delineados sin mucha claridad- dependen, sin embargo, de una auto-institucionalización en el ámbito de los ordenamientos jurídicos estatales, todavía rígidamente delimitados territorialmente (y viceversa). Se impone, pues, antes la promoción internacional y transnacional de "Estados de derechos humanos" que la represión imperialista de "Estados contrarios a los derechos humanos".

(Trad. de Victoria Roca Pérez)

\section{Bibliografía}

ARATO, Andrew / BRUNKHORST, Hauke (2003): “Ausgeträumt, die Revolution von außen”, en: Frankfurter Rundschau, № 99, 29.04.2003, p. 11.

BENDIX, Reinhard (1969): Nation-Building and Citizenship. Studies of our Changing social order, Garden City, New York: Anchor (1. ed.: 1964).

BobBIo, Norberto (1992): A Era dos Direitos, trad. de Carlos Nelson Coutinho, Rio de Janeiro: Campus.

BÖCKENFÖRDE, Ernst-Wolfgang (1999): “Ist Demokratie eine notwendige Forderung der Menschenrechte?”, in: Stefan Gosepath/Georg Lohmann (eds.), Philosophie der Menschenrechte, 2. ed., Frankfurt am Main: Suhrkamp, pp. 233-243.

BouRdiEu, Pierre (1971): "Genèse et structure du champ religieux", en: Revue française de Sociologie, Vol. XII, Nº 3 (Paris: Editions du C.N.R.S.), pp. 295334.

- (1982): Ce que parler veut dire: l'économie des échanges linguistiques, Paris: Fayard.

- (1989): La noblesse d'État: Grandes écoles et esprit de corps, Paris: Édtions de Minuit. 
BOURDIEU, Pierre / PASSERON, Jean-Claude (1970): La reproduction: éléments pour une théorie du système d'enseignement, Paris: Les Éditions de Minuit.

BRUnKHORST, Hauke (1999): "Heterarchie und Demokratie”, in: Hauke Brunkhorst/ Peter Niesen (eds.), Das Recht der Republik, Frankfurt am Main: Suhrkamp, pp. 373-385.

- (2000): Einführung in die Geschichte politischer Ideen, München: Fink.

- (2002): Solidarität: Von der Bürgerfreundschaft zur globalen Rechtsgenossenschaft, Frankfurt am Main: Suhrkamp.

BRUnKHORST, Hauke / KÖHLER, Wolfgang R. / LutZ-BACHMAnN, Matthias (eds.), (1999): Recht auf Menschenrechte: Menschenrechte, Demokratie und internationale Politik, Frankfurt am Main: Suhrkamp.

CAssiRER, Ernst (1944): An Essay on Man: An Introduction to a Philosophy of Human Culture, New Haven: Yale University Press. Trad. bras. (1972): Antropologia Filosófica - Ensaio sobre o Homem: Introdução a uma Filosofia da Cultura Humana, São Paulo: Mestre Jou.

- (1988): Philosophie der symbolischen Formen, vol. I, 9. ed., Darmstadt: Wissenschaftliche Buchgesellschaft (Reimpresión de la 2. ed. de 1953).

Comparato, Fábio Konder (1999): A Afirmação Histórica dos Direitos Humanos, São Paulo: Saraiva.

DELCAS, Marie (2002): "Opposition et officiers rebelles appellent à « libérer » le Venezuela”, en: Le Monde, № 17962, 25.10.2002, p. 5.

ECO, Umberto (1984): Semiotica e filosofia del linguaggio, Torino: Einaudi. Trad. bras. (1991): Semiótica e Filosofia da Linguagem, São Paulo: Ática.

Edelman, Murray (1967): The Symbolic Uses of Politics, Urbana / Chicago / Londres: University of Illinois Press.

- (1977). Political Language: Words that Succeed and Policies that Fail, New York / San Francisco / London: Academic Press.

FAORO, Raymundo (1976): Machado de Assis: a pirâmide e o trapézio, 2. ed., São Paulo: Editora Nacional / Secretaria de Cultura Ciência e Tecnologia do Estado de São Paulo.

FAssbender, Bardo (1998): "The United Nations Charter as Constitution of the International Community”, in: Columbia Journal of Transnational Law, vol. 36, $\mathrm{N}^{\circ} 3$ (New York: The Columbia Journal of Transnational Law Association), pp. 529-619.

FISCHER-LESCANO, Andreas (2002a): "Globalisierung der Menschenrechte”, in: Blätter für deutsche und internationale Politik, 10/2002 (Bonn: Blätter Verlagsgesellschaft), pp. 1236-1244.

- (2002b): “Globalverfassung: Verfassung der Weltgesellschaft”, en: Archiv für Rechts- und Sozialphilosophie 88 (Stuttgart: Franz Steiner Verlag), pp. 349378.

GAUCHET, Marcel (1989): La Révolution des droits de l'homme, Paris: Gallimard.

GERHARDT, Volker (1999): "Menschenrecht und Rhetorik”, en: BRUNKHORST / KÖHLER / LUTZ-BACHMANN (eds.), 1999: 20-40.

Gusfield, Joseph R. (1967): "Moral Passage: The Symbolic Process in Public Designations of Deviance”, en: Social Problems, vol. 15, N 2 (Detroit, Michigan: Society for the Study of Social Problems), pp. 175-188. 
- (1986): Symbolic Crusade: Status Politics and the American Temperance Movement, 2. ed., Urbana / Chicago: University of Illinois Press (1. ed.: 1963).

HABERMAS, Jürgen (1992): Faktizität und Geltung: Beiträge zur Diskurstheorie des Rechts und des demokratischen Rechtsstaats, Frankfurt am Main: Suhrkamp.

- (1996): Die Einbeziehung des Anderen: Studien zur politischen Theorie, Frankfurt am Main: Suhrkamp.

- (1998a): Die postnationale Konstellation: Politische Essays, Frankfurt am Main: Suhrkamp.

- (1998b): "Jenseits des Nationalstaats? Bemerkungen zu Folgeproblemen der wirtschaftlichen Globalisierung”, en: Ulrich Beck (ed.), Politik der Globalisierung, Frankfurt am Main: Suhrkamp, pp. 67-84.

- (1999a): “Zur Legitimation durch Menschenrechte”, en: Hauke Brunkhorst / Peter Niesen (eds.), Das Recht der Republik, Frankfurt am Main: Suhrkamp, pp. 386-403.

- (1999b): Wahrheit und Rechtfertigung: Philosophische Aufsätze, Frankfurt am Main: Suhrkamp.

- (2000): "Bestialität und Humanität: Ein Krieg an der Grenze zwischen Recht und Moral”, en: Reinhard Merkel (ed.), Der Kosovo-Krieg und das Völkerrecht, Frankfurt am Main: Suhrkamp, pp. 51-65.

- (2003): “Was bedeutet der Denkmalsturz?”, en: Frankfurter Allgemeine Zeitung, No 91, 17.05.2003, p. 33.

- (2004): „Wege aus der Weltunordnung: Ein Interview mit Jürgen Habermas“, en: Blätter für deutsche und internationale Politik 1/2004 (Bonn: Blätter Verlagsgesellschaft), pp. 27-45.

HÖFFE, Otfried (2002a): Demokratie im Zeitalter der Globalisierung, München: Beck.

- (2002b): "Globalität statt Globalismus. Über eine subsidiäre und föderale Weltrepublik”, en: Matthias Lutz-Bachmann / James Bohman (eds.), Weltstaat oder Staatenwelt? Für und wider die Idee einer Weltrepublik, Frankfurt am Main: Suhrkamp, pp. 8-31.

Hofstadter, Douglas R. (1979): Gödel, Escher, Bach: an Eternal Golden Braid, Hassocks: The Harvester Press. Trad. bras. (2001): Gödel, Escher, Bach: Um Entrelaçamento de Gênios Brilhantes, Brasília: Editora Universidade de Brasília / São Paulo: Imprensa Oficial do Estado.

KANT, Immanuel (1993): “Zum ewigen Frieden: Ein Philosophischer Entwurf”, en: idem, Werkausgabe, vol. XI: Schriften zur Anthropologie, Geschichtsphilosophie, Politik und Pädagogik 1, ed. por Wilhelm Weischedel, 10. ed., Frankfurt am Main: Suhrkamp, pp. 191-251 (1. ed.: Königsberg 1795).

KindermanN, Harald (1988): “Symbolische Gesetzgebung”, en: Dieter Grimm / Werner Maihofer (eds.), Gesetzgebungstheorie und Rechtspolitik (Jahrbuch für Rechtssoziologie und Rechtstheorie 13), Opladen: Westdeutscher Verlag, pp. 222-245.

- (1989): "Alibigesetzgebung als symbolische Gesetzgebung”, in: Rüdiger Voigt (eds.), Symbole der Politik, Politik der Symbole, Opladen: Leske + Budrich, pp. 257-273. 
Koskenniemi, Martti (1998): “Die Polizei im Tempel - Ordnung, Recht und die Vereinten Nationen: Eine dialektische Betrachtung”, en: Hauke Brunkhorst (ed.): Einmischung erwünscht? Menschenrechte und bewaffneten Intentionen, Frankfurt am Main: Fischer, S. 63-87.

- (2002): The Gentle Civilizer of Nations: The Rise and Fall of International Law 1870-1960, Cambridge: Cambridge University Press.

LACLAU, Ernesto (1994): “Why do Empty Signifiers Matter to Politics?”, in: Jeffrey Weeks (eds.), The Lesser Evil and the Greater Good. The Theory and Politics of Social Diversity, London: Rivers Oram Press, pp. 167-178.

LADEUR, Karl-Heinz (1992): Postmoderne Rechtstheorie: Selbstreferenz - Selbstorganisation - Prozeduralisierung, Berlin: Duncker \& Humblot.

LAfer, Celso (1988). A Reconstrução dos Direitos Humanos: Um Diálogo com o Pensamento de Hanna Arendt, São Paulo: Companhia das Letras.

- (1999): “Direitos Humanos”, en: Idem, Comércio, Desarmamento, Direitos Humanos: Reflexões sobre uma Experiência Diplomática, São Paulo: Paz e Terra, pp. 139-200.

LALANDE, André (ed.) (1992): Vocabulaire technique et critique de la Philosophie, 2a ed., vol. 2, Paris: Quadrige / Presses Universitaires de France (edición original, en fascículo, en Bulletin de la Société française de Philosophie, 19021923).

LEFORT, Claude (1981). “Droit de l'homme et politique”, en: Idem, L'Invention Démocratique: Les limites de la domination totalitaire, Paris: Fayard, pp. 45-83.

Trad. bras. (1987): "Direitos do homem e política”, en: A Invenção democrática: Os Limites do Totalitarismo, 2. ed., São Paulo: Brasiliense, pp. 37-69.

LÉVI-STRAuSs, Claude (1958): Anthropologie Structurale, Paris: Plon.

- (1973): “Introduction à l'œuvre de Marcel Mauss”, en: Marcel Mauss, Sociologie et Anthropologie, vol. I, 5. ed., Paris: Presses Universitaires de France, pp. IX-LII. Trad. bras. (1974): "Introdução à Obra de Marcel Mauss”, in: Marcel Mauss, Sociologia e Antropologia, vol. I, São Paulo: E. P. U. / EDUSP, pp. 136.

LOEWEnStein, Karl (1975): Verfassungslehre, 3. ed., Tübingen: Mohr.

LuHMANN, Niklas (1971): "Systemtheoretische Argumentationen: Eine Entgegnung auf Jürgen Habermas”, en: Jürgen Habermas / Niklas Luhmann, Theorie der Gesellschaft oder Sozialtechnologie - Was Leistet die Systemforschung?, Frankfurt am Main: Suhrkamp, 291-405.

- (1975): “Komplexität”, en: idem, Soziologische Aufklärung 2: Aufsätze zur Theorie der Gesellschaft, Opladen: Westdeutscher Verlag, pp. 204-20.

- (1981): Ausdifferenzierung des Rechts, Frankfurt a. M.: Suhrkamp.

- (1983). “Die Einheit des Rechtssystems”, en: Rechtstheorie 14 (Berlin: Duncker \& Humblot), pp. 129-154.

- (1984): “The Self-Reproduction of the Law and its Limits”, en: Felippe Augusto de Miranda Rosa (ed.), Direito e Mudança Social, Rio de Janeiro: OAB-RJ, pp. 107-128.

- (1986): Grundrechte als Institution: Ein Beitrag zur politischen Soziologie, 2. ed., Berlin: Duncker \& Humblot. 
- (1987a): Soziale Systeme: Grundriß einer allgemeinen Theorie, Frankfurt am Main: Suhrkamp.

- (1987b): Rechtssoziologie, 3. ed., Opladen: Westdeutscher Verlag.

- (1992): Beobachtungen der Moderne, Opladen: Westdeutscher Verlag.

- (1993a): "Das Paradox der Menschenrechte und drei Formen seiner Entfaltung”, en: Rechtsnorm und Rechtswirklichkeit: Festschrift für Werner Krawietz zum 60. Geburtstag, Berlin: Duncker \& Humblot.

- (1993b): Das Recht der Gesellschaft, Frankfurt am Main: Suhrkamp.

- (1997): Die Gesellschaft der Gesellschaft, Frankfurt am Main: Suhrkamp, 2 tomos.

- (1999): “Ethik in internationalen Beziehungen”, en: Soziale Welt 50 (Baden-Baden: Nomos), pp. 247-254.

- (2000): Die Politik der Gesellschaft, Frankfurt am Main: Suhrkamp.

LYOTARD, Jean-François (1979): La condition postmoderne, Paris: Minuit.

Marshall, T. H. (1976): Class, Citizenship, and Social Development, Westport, Connecticut: Greenwood Press (reimpresión de la edición de Nueva York, 1964).

MARX, Karl (1988): “Zur Judenfrage”, en: Karl Marx / Friedrich Engels, Werke, vol. I, 15. ed., Berlin: Dietz Verlag, pp. 347-377 (originariamente en: Deutsch-Französische Jahrbücher, Paris, 1844).

MAUS, Ingeborg (1997): “Staatssouveränität als Volkssouveränität. Überlegungen zum Friedensprojekt Immanuel Kants”, en: Wilfried Loth (ed.), Jahrbuch 1996 des Kulturwissenschaftlichen Instituts im Wissenschaftszentrum NRW, Essen: Altes Rathaus, pp. 167-194.

Michelman, Frank I. (1999): "Bedürfen Menschenrechte demokratischer Legitimation?”, en: BRUNKHORST / KÖHLER / LuTZ-BACHMANN (eds.), 1999: 52-65.

MÜLLER, Friedrich (1994): Strukturierende Rechtslehre, 2. ed., Berlin: Duncker \& Humblot.

- (1995): Juristische Methodik, 6. ed., Berlin: Duncker \& Humblot.

- (1997): Wer ist das Volk? Die Grundfrage der Demokratie. Elemente einer Verfassungstheorie VI, Berlin: Duncker und Humblot. Trad. bras. (1998): Quem é o Povo? A Questão Fundamental da Democracia, São Paulo: Max Limonad.

Neves, José Cavalcanti (1972): “A Ordem dos Advogados do Brasil e o Conselho de Defesa dos Direitos da Pessoa Humana - Exposição do Presidente”, en: Revista da Ordem dos Advogados do Brasil, ano IV, vol. IV (Rio de Janeiro: OAB/CF), agosto de 1972, pp. 173-180.

NeVEs, Marcelo (1992): Verfassung und Positivität des Rechts in der peripheren Moderne: Eine theoretische Betrachtung und eine Interpretation des Falls Brasilien, Berlin: Duncker \& Humblot.

- (1994a): A Constitucionalização Simbólica, São Paulo: Acadêmica.

- (1994b) "Entre Subintegração e Sobreintegração: A Cidadania Inexistente”, en: DADOS - Revista de Ciências Sociais 37/2 (Rio de Janeiro: IUPERJ), pp. 253276.

- (2000): Zwischen Themis und Leviathan: Eine Schwierige Beziehung - Eine Rekonstruktion des demokratischen Rechtsstaates in Auseinandersetzung mit Luhmann und Habermas, Baden-Baden: Nomos. 
- (2002): “Gerechtigkeit und Differenz in einer komplexen Weltgesellschaft", en: Archiv für Rechts- und Sozialphilosophie 88 (Stuttgart: Franz Steiner), pp. 323348

NYE, Joseph S. (1991): Bound to Lead: The Changing Nature of American Power, New York: Basic Books.

- (2002): The Paradox of American Power: Why the Word's only Superpower can't go it alone, Oxford: Oxford University Press.

Piovesan, Flávia (1996): Direitos Humanos e o Direito Constitucional Internacional, São Paulo: Max Limonad.

Provost, René (2002): International Human Rights and Humanitarian Law, Cambridge: Cambridge University Press.

RAWLS, John (1993): Political Liberalism, New York: Columbia University Press.

RusselL, Bertrand (1968): Logic and Knowledge -- Essays, 1901-1950, London / New York: Allen \& Unwin / Macmillan (1. ed.: 1956).

Teubner, Gunther (1996): "Altera Pars Audiatur: Das Recht in der Kollision anderer Universalitätsansprüche”, en: Archiv für Rechts- und Sozialphilosophie, Suplemento [Beiheft] 65 (Wiesbaden: Steiner), pp. 199-220.

- (2000): "Privatregimes: Neo-Spontanes Recht und duale Sozialverfassungen in der Weltgesellschaft”, en: Dieter Simon / Manfred Weiss (eds.), Zur Autonomie des Individuums. Liber Amicorum Spiro Simitis, Baden-Baden: Nomos, pp. 437-453.

- (2003): "Globale Zivilverfassungen: Alternativen zur staatszentrierten Verfassungstheorie”, en: Zeitschrift für ausländisches öffentliches Recht und Völkerrecht 63/1 (Heidelberg: Max Planck Institut für ausländisches öffentliches Recht und Völkerrecht), pp. 1-28.

WeLsCH, Wolfgang (1991): “Gesellschaft ohne Meta-Erzählung?”, en: Wolfgang Zapf (ed.), Die Modernisierung moderner Gesellschaften: Verhandlungen des 25. Deutschen Soziologentages in Frankfurt am Main 1990, Frankfurt am Main / New York: Campus, pp. 174-184.

- (1996): Vernunft: Die zeitgenössische Vernunftkritik und das Konzept der transversalen Vernunft, 2. ed., Frankfurt am Main: Suhrkamp.

WitTGenstein, Ludwig (1997): "Philosophische Untersuchungen” [1945-1949], en: Idem, Werkausgabe, vol. 1, 11. ed., Frankfurt am Main: Suhrkamp, pp. 225618.

Zolo, Danilo (1993): “Democratic Citizenship in a Post-communist Era”, en: David Held (ed.), Prospect for Democracy: North, South, East, West, Cambridge: Polity Press, pp. 254-268. 